Review Article

\title{
An In Vitro and In Vivo Comparison of Osteogenic Differentiation of Human Mesenchymal Stromal/Stem Cells
}

\author{
Jamie Mollentze $(\mathbb{D}$, Chrisna Durandt $\mathbb{D}$, and Michael S. Pepper $\mathbb{D}$ \\ Institute for Cellular and Molecular Medicine, Department of Immunology; SAMRC Extramural Unit for Stem Cell Research \\ and Therapy, Faculty of Health Sciences, University of Pretoria, Pretoria, South Africa
}

Correspondence should be addressed to Michael S. Pepper; michael.pepper@up.ac.za

Received 16 March 2021; Revised 23 July 2021; Accepted 20 August 2021; Published 8 September 2021

Academic Editor: LAURA DE GIROLAMO

Copyright (c) 2021 Jamie Mollentze et al. This is an open access article distributed under the Creative Commons Attribution License, which permits unrestricted use, distribution, and reproduction in any medium, provided the original work is properly cited.

\begin{abstract}
The use of stem cells in regenerative medicine, including tissue engineering and transplantation, has generated a great deal of enthusiasm. Mesenchymal stromal/stem cells (MSCs) can be isolated from various tissues, most commonly, bone marrow but more recently adipose tissue, dental pulp, and Wharton's jelly, to name a few. MSCs display varying phenotypic profiles and osteogenic differentiating capacity depending and their site of origin. MSCs have been successfully differentiated into osteoblasts both in vitro an in vivo but discrepancies exist when the two are compared: what happens in vitro does not necessarily happen in vivo, and it is therefore important to understand why these differences occur. The osteogenic process is a complex network of transcription factors, stimulators, inhibitors, proteins, etc., and in vivo experiments are helpful in evaluating the various aspects of this osteogenic process without distractions and confounding variables. With that in mind, the results of in vitro experiments need to be carefully considered and interpreted with caution as they do not perfectly replicate the conditions found within living organisms. This is where in vivo experiments help us better understand interactions that might occur in the osteogenic process that cannot be replicated in vitro. Potentially, these differences could also be exploited to develop an optimal MSC cell therapeutic product that can be used for bone disorders. There are many bone disorders, most of which cause a great deal of discomfort. Clinically acceptable protocols could be developed in which MSCs are used to aid in bone regeneration providing relief for patients with chronic pain. The aim of this review is to examine the differences between studies conducted in vitro and in vivo with regard to the osteogenic process to better define the gaps in current osteogenic research. By better understanding osteogenic differentiation, we can better define treatment strategies for various bone disorders.
\end{abstract}

\section{Introduction}

In vitro experiments have increased in complexity over the past several years from the use of omic technologies to study the cellular activity of primary cells to immortalized cells that overexpress telomerase allowing one to create human cell lines with normal or abnormal phenotypes. They have been also allowed for the use of stromal/stem cells that have the ability to differentiate into various tissues under the influence of diverse stimuli outside the living organism. There have also been advances in bioengineering/material science that have allowed for the development of in vitro multiorgan systems. All of these in vitro developments have allowed us to better understand the mechanisms of how cells operate under set experimental conditions at relatively low cost. These in vitro models have helped us to study a wide range of diseases and have provided the basis for many treatment strategies. However, many of these treatment strategies have also fallen short when tested in animal/human studies, as in vitro studies isolate specific process which do not represent what is truly happening within an organism. In vivo models should bridge this gap. For an in vivo model to be successful, it should reflect the physiology and biomechanics of certain aspects of what happens within the human body. 
True stem cells are defined as undifferentiated cells which simultaneously possess self-renewal and differentiation ability. Their capacity to differentiate into several cell types has solicited a great deal of interest in the fields of celland gene-based therapy, and regenerative medicine [1]. Langer and Vacanti [2] defined tissue engineering as "an interdisciplinary field that applies the principles of engineering and life sciences toward the development of biological substitutes that restore, maintain, or improve tissue function". Regenerative medicine, therefore, largely depends on the ability of stem cells to differentiate into the cell type of interest, replacing damaged or dysfunctional cells at the site of injury, and in so doing, restoring structure and function to the damaged tissue or organ [3]. The development of tissue engineering that specifically focusses on bone regeneration is important for bony defects and also when a fractured bone does not heal resulting in a nonunion [4]. Bone regeneration is a lengthy and complicated process, and orthopaedic surgeons often face bone regeneration that is suboptimal. The ability of mesenchymal stromal/stem cells (MSCs) to differentiate into osteoblasts has prompted surgeons and researchers to investigate the use of MSCs, in combination with a biomaterial scaffold, to improve bone repair and regeneration [5]. The use of MSCs in vitro to study the osteogenic process can help simplify this complex process and help us study individual processes that occur throughout osteogenesis. However, in vivo osteogenic experiments are equally if not more important to understand the osteogenic process as a whole.

\section{Osteogenesis}

Osteogenesis can be divided into intramembranous and endochondral ossification processes. Intramembranous ossification occurs in the craniofacial bones and clavicle and involves the direct differentiation of MSCs into osteocytes to form bone, while endochondral ossification involves the differentiation of MSCs into chondrocytes to form cartilage, which then forms a template for bone formation. Endochondral ossification is responsible for the formation of the long, short, and irregular bones that form part of the axial and appendicular skeleton [6].

Bone is a highly dynamic tissue and involves the constant build up and breakdown of bone tissue known as bone remodelling. Bone is composed of both cells (osteocytes, osteoblasts, and osteoclasts) and an extracellular matrix that is mineralized by the deposition of calcium hydroxyapatite [7]. Bone matrix homeostasis is monitored and maintained by mature bone cells known as osteocytes [8]. When matrix microdamage occurs, such as in a fracture, disruption of osteocyte canaliculi leads to the paracrine release of cytokines and other mediators by osteocytes, attracting osteoclasts to the site of injury/defect $[9,10]$. Osteoclastogenesis (osteoclast differentiation) from mononuclear osteoclast precursors can also be induced by the secretion of receptor activator of nuclear factor kappa-B ligand (RANKL) and macrophage-colony stimulating factor (M-CSF) by surrounding stromal and osteoblast cells $[11,12]$. Osteoclasts secrete a collagen-digesting enzyme and an acidic hydrogen ion mixture that dissolves the calcium phosphate in the defective bone tissue, a process known as bone resorption [13]. Once the defective bone tissue is cleaned out, macrophage-like cells smooth the resorbed bone tissue in preparation for matrix deposition [12]. Osteoclasts then recruit bone-forming cells termed osteoblasts before they undergo apoptosis. Osteoblasts are responsible for synthesizing components of the bone matrix, such as type I collagen, proteoglycan, and alkaline phosphatase (ALP), to name a few [7]. By balancing bone resorption and bone formation, bone homeostasis is maintained (Figure 1).

\section{Regulation of Osteogenesis}

Osteogenesis is controlled by a wide range of stimulators and inhibitors, which occur both at the transcriptional level and through extracellular signalling pathways. Runt-related transcription factor 2 (RUNX2) is an essential transcription factor that controls the differentiation of MSCs into osteoblasts [14]. Additionally, osteogenesis is regulated through changes in the osteoprotegerin (OPG)/RANKL ratio. RANKL binds to RANK, found on the surface of preosteoclasts, to induce differentiation of preosteoclasts into mature osteoclasts in the presence of M-CSF, leading to bone resorption [7]. Osteoclast differentiation needs to be blocked in order for osteoblast differentiation to occur; this happens through the secretion of OPG that acts as a soluble decoy receptor, which binds to RANKL, blocking RANKL/RANK interactions and thereby inhibiting osteoclast differentiation (Figure 1).

3.1. RUNX2: Master Regulator of Osteogenic Transcription. RUNX2 is the main molecular regulator responsible for the differentiation of MSCs into preosteoblasts and is expressed early to promote osteogenesis and inhibit adipogenesis and chondrogenesis [15]. RUNX2 regulates many downstream osteogenic genes such as Osterix (Osx), osteocalcin (Ocn), $\mathrm{ALP}, \beta$-catenin, core-binding factor- $1 \alpha(\mathrm{CBF}-1 \alpha)$, bone sialoprotein (BSP), osteonectin, osteopontin (Opn), and type I collagen, to name a few (Figure 2). Furthermore, activatio$\mathrm{n}$ /overexpression of RUNX2 results in a significant decrease in adipogenic-related transcription factors and enzymes, peroxisome proliferator-activated receptor $(\operatorname{PPAR} \gamma)$, and lipoprotein lipase (LPL) [16]. RUNX2 is downregulated during the later stages of bone maturation [15]. In vitro studies show that RUNX2 also directly regulates synthesis of both OPG and RANKL $[17,18]$. These findings have been confirmed in vivo [16, 19]. Otto et al. [19] showed that a mutation in the RUNX2 gene resulted in a complete absence of osteoblasts, which resulted in turn in a cartilaginous skeleton; RUNX2-deficient mice also die shortly after birth. A later study done by Adhami et al. [20] demonstrated that RUNX2 null mice were born alive and were identical to wildtype mice and only after a month did the RUNX2 null mice display poor growth, weighing 20-25\% less than their wildtype counterparts. With closer inspection, they found there was a $50 \%$ decrease in trabecular number and a $20 \%$ decrease in trabecular thickness indicating that the loss of RUNX2 led to significant growth deficits. They also noticed impaired bone mineralization due to a decrease in the 


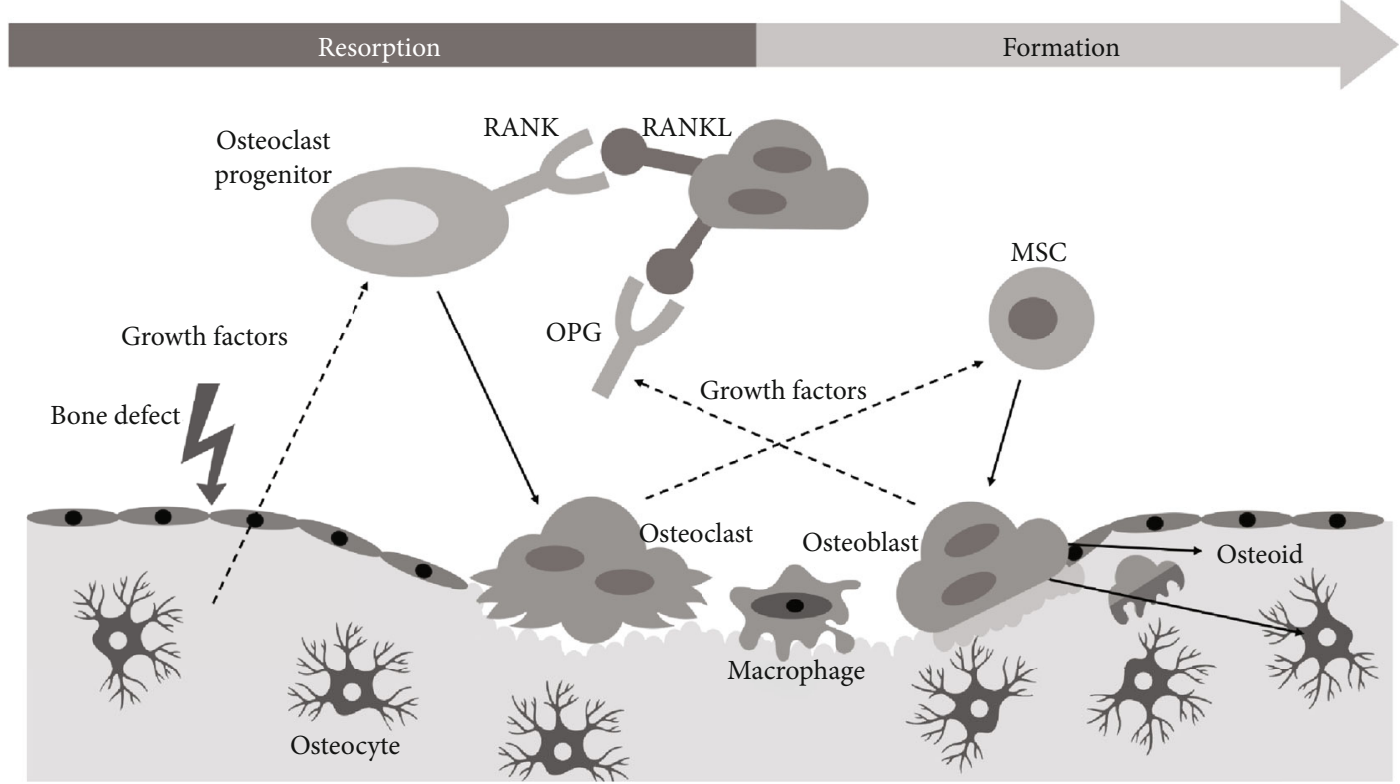

FIGURE 1: Schematic representation of the bone remodelling process. Solid lines indicate differentiation, and dotted lines indicate stimulation. Osteocytes within bone tissue stimulate osteoclast progenitor cells to differentiates into osteoclasts. Osteoblasts can also stimulate osteoclast progenitor cells through RANK/RANKL binding. Once the defective bone tissue is cleared, macrophage-like cells smooth the resorbed bone tissue. Before undergoing apoptosis, osteoclasts recruit osteoblasts for matrix deposition. Osteoblasts stimulate the release of osteoprotegerin (OPG) that acts as a soluble decoy and inhibits osteoclast differentiation. Adapted from Wittkowske et al. [12], bone remodelling cycle, https://creativecommons.org/licenses/by/4.0/legalcode http://creativecommons.org/licenses/by/4.0/. MSC: mesenchymal stroma/stem cell; RANK: receptor activator of nuclear factor kappa- $B$; RANKL: receptor activator of nuclear factor kappa$B$ ligand; OPG: osteoprotegerin.

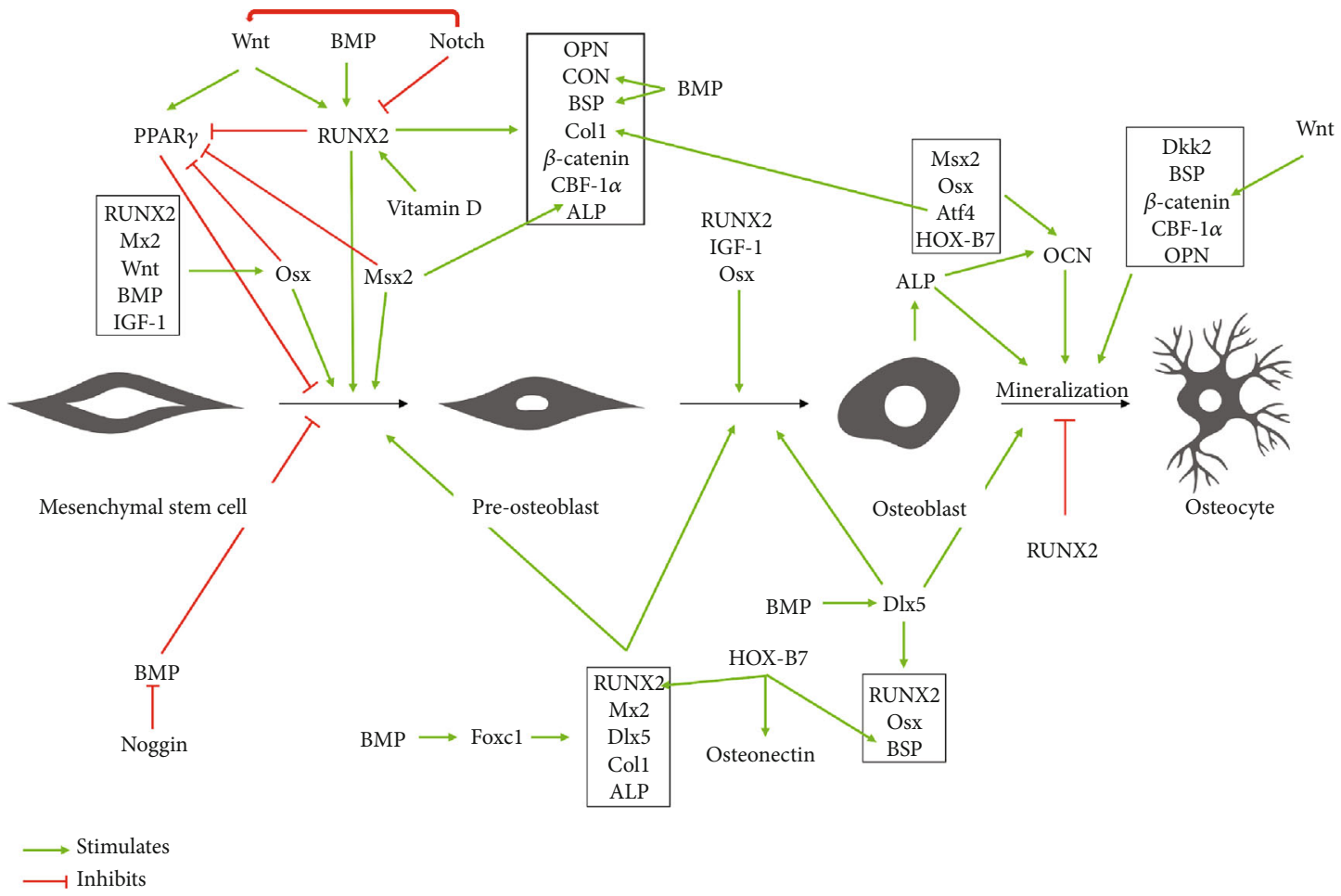

FIGURE 2: Regulation of MSC osteogenic differentiation. Green arrows indicate positive regulation while red lines indicate negative regulation. This figure illustrates the complex network of cells and mediators involved in bone formation. 
average density of hydroxyapatite. Together, these findings indicate that RUNX2 is important in bone formation. The difference between the two studies could be explained by differences in the strain of mice. On the other hand, Zhang et al. [16] demonstrated that the overexpression of RUNX2 in 4-week-old nude mice resulted in increased mineral deposition.

3.2. Early-Stage Osteogenic Regulators. Msx2 is a homeobox transcription factor that mainly controls the early stages of osteogenic differentiation but also plays a role in the later stages of osteoblastic mineralization. Ex vivo studies have shown that the expression of Msx2 promoted upregulation of Osx and ALP, but did not influence the expression of RUNX2 [21]. Cheng et al. [21] demonstrated the ability of Msx2 to regulate osteogenesis through the suppression $\operatorname{PPAR} \gamma$. Ocn, a late stage osteogenic marker, is downregulated in the early stages of osteogenesis through proteinprotein interactions between Msx2 and Ocn [22]. Satokata et al. [23] reported osteoblast deficiency leading to osteoporosis syndromes in Msx2 null mice, supporting the idea that Msx2 plays an important role in osteogenic differentiation. The insulin-like growth factor (IGF) axis regulates both osteoblast and osteoclast differentiation and is one of the most abundant growth factors in bone tissue [24]. Osteocytes upregulate IGF-1 in response to mechanical loading; IGF-1 is thus considered to be an early osteogenic marker [25]. The knockout of IGF-1 in MSCs compromises the osteogenic process in vitro [26]. This study was corroborated by Zhang et al. [27] who showed that bone formation was completely blocked by disrupting the $I g f 1$ gene in mature osteoblasts. Similarly, in vivo, a disruption in the Igfl gene inhibited periosteal expansion resulting in rodents with smaller body features [28].

Osx and activating transcription factor 4 (Atf4) are located downstream of RUNX2 and are both important transcription factors in osteogenesis. Atf4 regulates osteogenesis through its ability to regulate $\mathrm{Ocn}$ and collagen type I. Deletion of Atf4 in mice led to impaired terminal osteoblast differentiation and resulted in severe osteopenia and other defects during skeletal development [29, 30]. Osx is a potent bone forming stimulator that is part of the specificity protein 1 family [31]. Osx stimulates osteoblastic differentiation in MSCs through the repression of $\operatorname{PPAR} \gamma$, which inhibits adipogenesis [32]. Several in vivo studies have demonstrated the indispensable function of Osx in osteogenic differentiation [31, 33-35]. The importance of Osx was demonstrated by Hilton et al. [33]: inhibition of Osx impairs osteoblast mineralization of cartilage into bone. In vitro studies suggest that Osx is modulated by IGF-I, BMPs, Msx2, and the Wnt signalling pathway [31, 34, 35]. Overexpression of Osx in C2C12 cells resulted in increased expression of ALP and Ocn, leading to the calcification of bone tissue [31]. ALP plays an important role in phosphate metabolism by hydrolysing inorganic phosphate to promote matrix calcification, thus playing a key role during osteogenesis [36]. Nakamura et al. [37] overexpressed ALP in wildtype osteoblast cells which resulted in increased expression of osteogenic genes RUNX2, Osx, Ocn, and dentin matrix acidic phosphoprotein 1 (Dmp1), an osteocyte differentiation marker. Consistent with Nakamura et al.'s [37] in vitro study, Narisawa et al. [38] demonstrated that the overexpression of ALP by osteoblasts resulted in an increase in bone mineralization in vivo. ALP-/- mice exhibit long bone and skull fusion defects, and by administering exogenous ALP, the authors were able to increase bone density and the life span of these mice [38-42]. Another earlystage osteogenic marker is COL1A1. Mutations in COL1A1 have been studied extensively in osteogenesis imperfecta, a genetic disorder that results in bone fragility and multiple fractures. COL $1 A 1$ is important for the synthesis of collagen type I which is a major component of bone extracellular matrix (ECM) and is expressed in all osteoblastic cells throughout osteogenic differentiation, and mutations lead to ineffective or absent differentiation $[43,44]$.

3.3. Late-Stage Osteogenic Regulators. Transcription factors involved in the later stages of osteogenesis regulate terminal differentiation and are involved in mineralization. Some of the most important late-stage transcription factors are Opn, distal less homeobox 5 (Dlx5), Ocn, OPG, and BSP, to name a few. Opn is a matricellular protein that belongs to the small integrin-binding ligand N-linked glycoprotein (SIBLING) family and is involved in mineralization in response to mechanical stress. Chen et al. [45] observed that Opn-/- MSCs form considerably less bone tissue in vitro compared to their wild-type counterparts; however, the same is not true in vivo. Chen et al. [45] suggest that the difference between in vitro and in vivo studies may reflect functional redundancy and that other members of the SIBLING family can compensate for Opn deficiency. Interestingly, however, Opn-/- mice did show a higher fat weight/body weight ratio. Dlx5 is another bone inducing transcription factor that plays a role in the later stages of osteogenesis. In vitro studies show that by inhibiting Dlx5, RUNX2 and Osx expression was blocked, suggesting that Dlx5 may be an upstream regulator of RUNX2 and Osx. Dlx5 is also a downstream target of BMP signalling [46]. Additionally, upregulation of Dlx5 did not increase the osteogenic markers ALP and Ocn in vitro. Other cell culture studies demonstrated however that overexpression of Dlx 5 increases expression of Ocn [47]. Dlx5 null osteoblasts display a higher RANKL/OPG ratio, suggesting that Dlx5-deficient osteoblasts are able to induce osteoclastogenesis [48]. Dlx5deficient mice displayed delayed and abnormal osteogenesis, resulting in severe craniofacial abnormalities as well as a decrease in RUNX2, Osx, Ocn, and BSP expression [48, 49]. An increase in the number of osteoclasts was observed in the femurs of Dlx 5 null mice [50]. Bone defects were also present in Dlx5/Dlx6 double knockout mice, further indicating that Dlx5 plays an important role in bone mineralization [50]. Interestingly, the forced overexpression of Dlx 5 in vivo also resulted in reduced bone mineralized matrix deposition despite high levels of RUNX2 and BSP expression, suggesting a block in the later stages of osteogenesis [51].

OPG is expressed by osteoblasts, MSCs, and endothelial cells and can enhance osteogenesis by acting as a decoy receptor for RANKL, inhibiting osteoclastogenesis [52, 53]. 
Both in vitro and in vivo models have demonstrated that OPG levels are inversely related to osteoclastogenesis [54, 55]. In an in vitro study, the treatment of undifferentiated MSCs with OPG resulted in the enhancement of osteogenesis [56]. Furthermore, OPG knockout mice demonstrate an increase in bone resorption due to increased osteoclast activity [57].

Ocn and BSP are both noncollagenous proteins found in bone tissue. Ocn is the most abundant, noncollagenous protein in bone tissue and is used as a biochemical marker for bone formation in vitro and in vivo: an increase in Ocn levels has been associated with an increase in bone mineral density [58]. BSP is found in mineralized tissue such as bone, calcified cartilage, and dentin and makes up approximately $8 \%$ of the noncollagenous protein of bone [59]. Although the function of BSP is not yet fully known, it is suspected to play a role in the formation of hydroxyapatite (essential component of healthy bone tissue) [60]. In the absence of BSP in vitro, osteogenic differentiation is negatively impacted. BSP overexpression leads to an increase in osteoblastrelated gene expression as well as enhanced mineralization. The opposite is also true; when BSP expression is reduced, there is both a reduction in osteoblast-related gene expression and bone mineralization [61]. In vitro studies have suggested that a lack of BSP reduces osteoprogenitor cell numbers and has a compensatory role on Opn. The BSP-/phenotype is associated with the upregulation of Opn in an attempt to rescue the cells. However, the overexpression of Opn is not enough to rescue the cells, and thus, bone formation and mineralization do not occur $[62,63]$. BSP-/- mice demonstrate normal skeletal development; however, they display undermineralization of long bones $[63,64]$.

3.4. Additional Osteogenic Transcription Factors. Other transcription factors that are involved in osteogenic differentiation are frizzled-related protein (FRZB), dickopf (Dkk) 2, homeobox protein Hox-B7 (HOXB7), $\beta$-catenin, and others. FRZB is a Wnt modulator that increases the expression of osteogenic-related markers and calcium deposition. The overexpression of Frzb in MC3T3-E1 cells increases osteogenic activity while the loss of Frzb results in a decrease in osteogenic activity [65]. However, Frzb null mice show an increase in cortical bone thickness [66]. These contrasting results may be explained by the deficiency of FRZB leading to supraphysiological levels of other Wnt modulators such as Dkk1 and Dkk2 that stimulate osteogenesis. Dkk1 and Dkk2 work antagonistically in vivo, where the increased expression of Dkk1 results in a decrease in bone mass while an increase in Dkk2 expression positively stimulates bone formation $[67,68]$.

When the transcription factor HOXB7 is over expressed, osteogenesis is enhanced through the upregulation of RUNX2 [69]. Gao et al. [69] performed both in vitro and in vivo studies to investigate the role of HOXB7 during osteogenic differentiation. In their in vitro studies, the overexpression of HOXB7 enhanced bone mineralization through activation of ALP. HOXB7 overexpression also had an effect on other osteogenic transcription factors and proteins such as RUNX2, osteonectin, collagen type I, BSP, and Ocn, lead- ing to the promotion of osteogenesis. In contrast, when HOXB7 was inhibited, these transcription factors were downregulated resulting in a decrease in ALP activity that led to a decrease in mineralization. Other HOX genes involved in osteogenesis are $\mathrm{HOXa} 2$ and $\mathrm{HOXd}$ 9. In vivo studies showed that during bone regeneration, $\mathrm{HOXa} 2$ is upregulated after bone fracture while HOXd9 is downregulated [70].

The $\beta$-catenin protein is multifunctional. One important function is its ability to regulate the transduction of Wnt signalling [71]. The inhibition of $\beta$-catenin leads to the inhibition of osteogenesis and the promotion of chondrogenesis [72]. $\beta$-catenin is activated by the Wnt signalling pathway; $\beta$-catenin then interacts with LEF/TCF which together increase bone mineralization [73]. Ex vivo studies have demonstrated the importance of $\beta$-catenin in osteoblast mineralization through its downstream regulation of BMP2 [74]. In an in vivo study, Hill et al. [75] knocked-down $\beta$-catenin from head and limb mesenchyme in mouse embryos. In the absence of $\beta$-catenin, the mutant mice did not form cortical or trabecular bone. Interestingly, the overexpression of $\beta$-catenin does not result in an increase in osteoblast number, but rather inhibits chondrogenesis and allows for MSC osteogenesis [75].

There are several other transcription factors, not discussed in this review, that are involved in osteogenesis. These include matrix extracellular phosphoglycoprotein (MEPE), human high-temperature requirement protein 1 (HTRA1), IGFBP-2, and secreted protein acidic and rich in cysteine (SPARC), TMEM119, sclerostin, and hypoxiainducible factor- $1 \alpha$ (HIF- $1 \alpha$ ); for further information, please refer to [76-83].

The osteogenic process involves a complex network of cells and mediators, and even the slightest disruption of the network leads to defective bone formation (Figure 2).

3.4.1. Signalling Pathways. Successful translation of in vitro findings to clinical applications in vivo requires a good understanding of potential differences in events during in vitro and in vivo regulation of osteogenic differentiation. The BMP pathway and the $\mathrm{Wnt} / \beta$-catenin signalling pathway are two important extracellular signalling pathways involved in osteogenic differentiation $[72,84]$. Several studies have investigated the role of the BMP pathway during in vitro and in vivo osteogenic differentiation and reported on the differences and similarities in extracellular signalling pathways regulating events in these settings. Tsialogiannis et al. [85] concluded that the BMP pathway plays an important role during both in vitro and in vivo osteogenic differentiation. The majority of studies looking at the relationship between the Wnt/ $\beta$-catenin signalling pathway and bone formation have been done in vivo. Other extracellular signalling pathways that play a role in osteogenesis are the Notch signalling pathway, the hedgehog pathway, fibroblast growth factor (FGF), vascular endothelial growth factor (VEGF), and extracellular signal-regulated kinase [86] (Figure 3).

3.5. BMP Signalling Pathway. BMP binds to its receptor, BMPR, found on epithelial cells, which in turn activates 


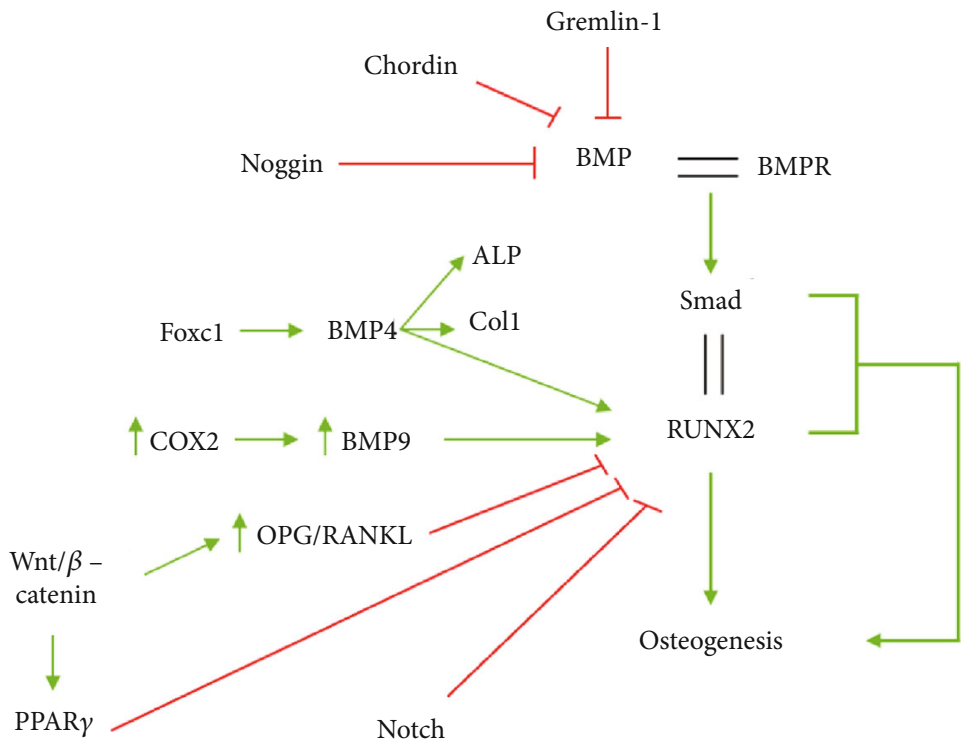

FIGURE 3: Illustration of how various signalling pathways regulate osteogenesis through the master regulator of osteogenesis, RUNX2. Green arrows indicate positive regulation while red lines indicate negative regulation.

the intracellular transcription factor Smad. Smad binds to the master regulator, RUNX2. The Smad-RUNX2 complex induces osteogenesis [87] (Figure 3). Using various BMP antagonists in vitro, Tsialogiannis et al. [85] demonstrated that inhibition of BMP function affects multiple downstream factors, such as RUNX2, BSP, and Ocn. The investigators extended their investigation by overexpressing noggin, a BMP antagonist, in transgenic mice and reported a significant decrease in bone density and bone formation in these animals [88]. In contrast, complete knockout of noggin led to irregularly thickened bones and death shortly after birth $[85,89]$. Other BMP antagonists include chordin and gremlin. Multiple in vitro studies have demonstrated that chordin is a strong endochondral ossification stimulator [90-93]. Zhang et al. [94] examined the role of chordin in vivo and their results show that BMP-2 enhances maturation of chondrocytes resulting in growth of the growth plate of Hamburger-Hamilton stage 25-27 embryonic chick limbs. When chordin (a BMP antagonist) was expressed ectopically, it resulted in a delayed growth rate of the growth plate by binding to BMP to inhibit BMP's function. From previous in vitro studies it is known that when gremlin-1 is suppressed, the expression of osteoblastic genes ALP, BSP, MSX2, OC, OPN, and RUNX2 is significantly increased [95]. It was only recently that the role of gremlin was investigated in vivo. Rowan et al. [96] explored the effect of Grem 1 deletion in ROSA26CreER-Grem $1 \mathrm{flx} / \mathrm{flx}$ mice. Although these mice demonstrated normal bone structure, there were other abnormalities present including severe bowel disruption as well as abnormal haematopoiesis. Cyclooxygenase 2 (COX-2) enhances in vitro osteogenic differentiation through initiating the BMP signalling pathway via a positive regulatory loop with $\mathrm{BMP} 9$, a potent osteogenic stimulator [97, 98]. Wang et al. [98] demonstrated that COX-2 is critical for orchestrating the BMP/Smad signalling pathway in vitro (Figure 3 ). Silencing Cox2 downregulated the expression of RUNX2 and Dlx-5. Similarly, in vivo studies showed that COX-2 knockout mice displayed 98\% and $86 \%$ reduction in bone formation when they received a bone graft from other COX-2 knockout mice or wild type mice, respectively [99].

Foxc1 is another important osteogenic regulator that interacts with an osteogenic factor, BMP4. Foxc1 mutant mice display numerous abnormalities related to bone development. The calvarial bones and sternum are absent, the ribs are deformed, and the skull base is reduced in size [100, 101]. The ectopic expression of Foxc1 in C2C12 myoblasts resulted in the rescue of osteogenesis by increasing ALP activity and inducing early osteogenic markers such as RUNX2 and type I collagen [102]. Furthermore, Hopkins et al. [103] demonstrated that a downregulation of Foxc1 in $\mathrm{C} 2 \mathrm{C} 12$ cells resulted in the inhibition of RUNX2, Msx2, and ALP activity (Figure 3). These investigators suggested that Foxc1 is required for the initiation of osteogenesis but not for the later stages, as they observed a decrease in Foxc1 levels as differentiation proceeded.

3.6. Wnt/ $\beta$-Catenin Signalling Pathway. Wnt/ $\beta$-catenin signalling, also known as the classical or canonical Wnt pathway, is of particular importance as it can either induce or inhibit osteogenesis. This pathway can regulate the expression of RUNX2 to induce osteogenesis. Alternatively, the Wnt pathway inhibits osteogenesis by altering the OPG/RANKL ratio. The expression of PPAR $\gamma$ is also controlled by the Wnt pathway. PPAR $\gamma$ is the main transcription factor in adipogenesis, and therefore, its expression needs to be inhibited in order for osteogenesis to occur [35] (Figure 3).

Mice lacking the Lrp5 gene, which codes for a Wnt coreceptor, developed osteopenia, while the overexpression of Lrp5 resulted in high-bone-mass syndromes [104, 105]. Genome-wide association studies in humans revealed an 
association between multiple mutations in Wnt1 and Wnt16 and early onset osteogenesis imperfecta and osteoporosis; both bone disorders result in brittle bones as well as an increased risk of fractures [106, 107]. Hilton et al. [33] removed all the components of the Notch network in mice, and this resulted in increased bone mass and a depleted pool of MSCs in the bone marrow [33]. The Notch network inhibits osteogenesis through the expression of HEY1 and HEYL transcription factors that directly inhibit RUNX2 (Figure 3). Overexpression of Notch-1 in mice inhibited osteogenesis through the inhibition of the $\mathrm{Wnt} / \beta$-catenin signalling pathway [108]. It is clear that extracellular signalling pathways play a major role in osteogenesis via a complex network of transcription factors. It is therefore important to examine the network as a whole and not separate out specific interactions, as would occur in an in vitro setting.

\section{Mesenchymal Stromal/Stem Cells}

MSCs contain a population of multipotent adult stem cells capable of differentiating into cell types of mesodermal origin [109]. MSCs were initially isolated from bone marrow (BM) and are in this setting referred to as bone marrowderived MSCs (BM-MSC) [110]. Since then, human MSCs have been isolated from various foetal and adult tissues, such as adipose tissue [111], the amniotic membrane [112], amniotic fluid [113], placental and foetal membranes [114], umbilical cord lining membrane [115], the endometrium [116], dental tissue [117], menstrual blood [118], peripheral blood [119], skin [120], synovial fluid [121], and Wharton's jelly [122].

It is well accepted that isolated MSC populations are heterogeneous, containing both stem cells and mature stromal cells. Even though the terms mesenchymal stem cells and mesenchymal stromal cells are used interchangeably [109], there are distinct differences between the two. Mesenchymal stem cells possess the ability to self-renew and differentiate, demonstrating the functionality of true stem cells, while mesenchymal stromal cells refers to a heterogeneous populations of progenitor cells at various stages of maturation. Directly after isolation, the isolated MSC population may also contain differentiated cells present in the tissue microenvironment such as endothelial cells, pericytes, fibroblasts, and immune cells, as well as elements of circulating blood [123-125].

\section{Characterization of MSCs}

All MSCs, independent of their source, should adhere to minimal criteria recommended by the International Society for Cellular Therapy (ISCT). These include (a) the ability to adhere to plastic; (b) the expression of a specific set of cell surface markers such as cluster of differentiation (CD)73, CD90, CD105 or CD13 and the lack of CD14, CD19, CD31, CD45, and human leukocyte antigen (HLA)-DR; and (c) the ability to differentiate into at least adipocytes, osteoblasts, and chondrocytes in vitro [126]. Many studies have suggested that the expression of CD34 is variable and therefore MSCs can either be positive or negative for CD34 [126-128]. Currently, there is no cell surface protein specific to MSCs, and MSCs isolated from different sources may differ regarding cell surface protein expression profiles. Table 1 summarizes the different cell surface markers that are associated with MSCs isolated from different tissue sites.

\section{Osteogenic Potential of MSCs In Vitro}

In vitro, MSCs are induced to undergo osteogenic differentiation following exposure to compounds such as $\beta$-glycerophosphate, dexamethasone, and ascorbate-2-phosphate, that promote cell proliferation and osteogenic differentiation. Although these 3 compounds ( $\beta$-glycerophosphate, dexamethasone, and ascorbate-2-phosphate) are present in all in vitro osteogenic media, there is a lack of consensus regarding the optimal medium for in vitro osteogenic differentiation of MSCs, particularly regarding the concentration of dexamethasone, which varies significantly between studies. Table 2 summarises the composition of the osteogenic media used most often. Ascorbic acid and dexamethasone are the main osteogenic inducing factors, and together increase the activity of ALP. Upregulation of ALP activity increases the speed at which bone differentiation occurs [129]. Ascorbate-2-phosphate is responsible for the synthesis of collagen in the early stages of osteogenesis, while $\beta$ glycerophosphate is responsible for mineralization in the later stages [130, 131]. Along with increasing ALP activity, dexamethasone also regulates the osteogenesis-related gene RUNX2 [132].

Various spectrophotometric assays are used to determine the extent of in vitro osteogenic differentiation. Both the Von Kossa assay and the Alizarin Red S (ARS) assay stain for calcium deposits that are present in bone tissue. The Von Kossa assay is a qualitative assay in which calcium is replaced with silver ions (source: silver nitrate solution) to form black/brown deposits that can be analysed under a microscope [133]. The ARS assay is semiquantitative in which ARS reacts with calcium to form a red deposit which is extracted using acetic acid. The extracted dye is spectrophotometrically quantified at $405 \mathrm{~nm}$ [134]. Another assay that is often used to quantify osteogenesis is the ALP assay that also uses spectrophotometry to measure the level of ALP activity. In short, 4-nitrophynylphosphate is used as a phosphate substrate for ALP which dephosphorylates 4nitrophenylphosphate which then turns yellow. This colour change is measured at $405 \mathrm{~nm}$ [135].

MSCs isolated from various tissues also differ in their differentiation capabilities [152-155]. This may be due to DNA methylation of key transcription factors. $\mathrm{Xu}$ et al. [152] demonstrated that MSCs retain their epigenetic memory and favour either of adipogenic or osteogenic differentiation, depending on their tissue of origin. In BM-MSCs, the CpG island in the RUNX2 promoter is hypomethylated while the $\mathrm{CPG}$ island in PPAR $\gamma$ is hypermethylated. The opposite is true in adipose tissue-derived stromal/stem cells (ASCs): the PPAR $\gamma$ promoter is hypomethylated while the RUNX2 promoter is hypermethylated. Pérez-Silos et al. and McLeod et al. [156, 157] suggest that MSCs consist of 
TABLE 1: Cell surface markers expressed by MSCs isolated from different tissues.

\begin{tabular}{|c|c|c|c|}
\hline \multirow{2}{*}{ Source } & \multicolumn{2}{|c|}{ Cell surface marker } & \multirow{2}{*}{ Reference } \\
\hline & Positive & Negative & \\
\hline Adipose tissue & $\begin{array}{l}\text { CD10, CD13, CD29, CD34, CD44, CD49e, CD59, CD71, } \\
\text { CD73, CD90, CD105, CD166, CD200, HLA-ABC }\end{array}$ & $\begin{array}{l}\text { CD11b, CD14, CD19, CD31, CD34, CD45, } \\
\text { CD56, CD146, CD235a, Stro1, HLA-DR }\end{array}$ & $\begin{array}{c}{[111,} \\
136-139]\end{array}$ \\
\hline $\begin{array}{l}\text { Amniotic } \\
\text { membrane and fluid }\end{array}$ & CD29, CD44, CD73, CD90, CD105, SH2-4 HLA-ABC & $\begin{array}{l}\text { CD11b, CD10, CD14, CD19, CD20, CD34, } \\
\text { CD45, CD79a, HLA-DR }\end{array}$ & $\begin{array}{c}{[113,} \\
140-142]\end{array}$ \\
\hline Bone marrow & CD29, CD44, CD73, CD90, CD105, CD271, Stro-1 & CD14, CD34, CD45, HLA-DR & $\begin{array}{l}{[57,126} \\
137,143]\end{array}$ \\
\hline Dental tissue & $\begin{array}{l}\text { CD29, CD34, CD44, CD73, CD90, CD105, CD105, } \\
\text { CD117, CD166, Stro1 }\end{array}$ & $\begin{array}{l}\text { CD11b, CD14, CD19, CD31, CD34, CD45, } \\
\text { CD79a, CD146, HLA-DR }\end{array}$ & $\begin{array}{c}{[117,} \\
143-145]\end{array}$ \\
\hline Endometrium & CD44, CD49d, CD479f, CD73, CD90, CD105, CD146 & CD14, CD19, CD34, CD45, HLA-DR & {$[116,146]$} \\
\hline Peripheral blood & CD29, CD73, CD90, CD105, CD106, CD146, CD166, & CD34, CD45, CD133 & $\begin{array}{c}{[119,147,} \\
148]\end{array}$ \\
\hline $\begin{array}{l}\text { Placental and foetal } \\
\text { membrane }\end{array}$ & CD29, CD73, CD90, CD105 & CD34, CD45 & {$[114]$} \\
\hline Skin & CD29, CD44, CD73, CD90, CD105, CD166 & CD14, CD34, CD45, HLA-DR & {$[120,149]$} \\
\hline Synovial fluid & CD44, CD73, CD90, CD105, CD147, Stro-1 & $\begin{array}{c}\text { CD11b, CD14, CD19, CD31, CD34, CD45, } \\
\text { CD79a, CD106, HLA-DR }\end{array}$ & {$[121,141]$} \\
\hline $\begin{array}{l}\text { Umbilical cord } \\
\text { lining membrane }\end{array}$ & CD29, CD44, CD73, CD90, CD105, CD106, HLA-I & CD14, CD31, CD34, CD45, HLA-DR & $\begin{array}{l}{[111,115,} \\
150]\end{array}$ \\
\hline $\begin{array}{l}\text { Wharton's jelly } \\
\text { within umbilical } \\
\text { cord }\end{array}$ & CD73, CD90, CD105 & CD14, CD19, CD34, CD45, CD79, HLA-DR & {$[122,151]$} \\
\hline
\end{tabular}

subpopulations that share common features while varying in the expression profile of their cell surface proteins, which can be related to differences in differentiation potential. Cantentin et al. [158] found that UC-MSCs produced significantly more ECM, while stronger staining for type I collagen was observed for BM-MSCs indicating that BMMSCs have enhanced osteogenic potential when compared to UC-MSCs. UC-MSCs produced molecules that BMMSCs did not such as type X collagen and the HtrAl gene product. UC-MSCs additionally displayed a higher proportion of CD73+ cells. The authors suggest that the difference in CD73 expression and the production of these atypical molecules are the major reason for differences in chondrogenic differentiation potential between BM-MSCs and UCMSCs.

Other factors that may influence the differentiation capabilities of MSCs include the age of the donor, the health of the donor, culture conditions, and method of isolation. Barboni et al. and Xin et al. [159, 160] both demonstrated a positive correlation between age and DNA methylation status. Barboni et al. [159] observed a correlation between gestational age of amniotic-derived MSCs and global DNA methylation status, which resulted in a decrease in osteogenic differentiation potential. Xin et al. [160] extensively compared DNA methylation status and multilineage differential capabilities. An age-related decline in ASC osteogenic differentiation was observed when ASCs from young and old donors were compared. In another study, the differentiation potential of BM-MSCs from patients with osteoarthritis (OA) was compared to MSCs isolated from a control group of a similar age: both the chondrogenic and adipogenic differentiation potential of BM-MSCs from OA patients were significantly decreased compared to controls, while the osteogenic potential was similar when BM-MSCs from OA patients and MSCs from the control group were compared [161].

He et al. $[174,175]$ demonstrated that the extracellular matrix is important in directing MSCs down a specific lineage: a hydroxyapatite- (HA-) collagen matrix was found to be superior to a HA-synthetic hydrogel for osteogenic differentiation. For chondrogenesis, the HA-synthetic hydrogel was preferred over the HA-collagen matrix. The HAcollagen matrix imitated the natural composition of bone and resembled the physical and chemical microenvironment found in the human body, thus favouring osteogenesis. The reason why the HA-synthetic hydrogel was favoured for chondrogenesis is not fully understood, as the HAsynthetic hydrogel does not imitate natural cartilage. Overall, the use of a matrix increased cell proliferation, adhesion, migration, and differentiation. The biomechanics of the MSC microenvironment also has an effect on differentiation capabilities. Gungordo et al. [176] concluded that rat BMMSCs progress to an adipogenic lineage under unstrained conditions on a softer polyacrylamide hydrogel film, while rat BM-MSCs seeded on a stiffer polyacrylamide hydrogel and under strained conditions are driven down the osteogenic lineage. The use of animal serum which contains xenoantigens is another culture condition that can affect differentiation potential, specifically osteogenic differentiation [177, 178]. Okajcekova et al. [179] compared three different osteogenic induction media and their differentiation capabilities, of which one was xeno-free. Not only did the xeno-free induction medium result in significantly greater osteogenic differentiation potential compared to the other two, but the 


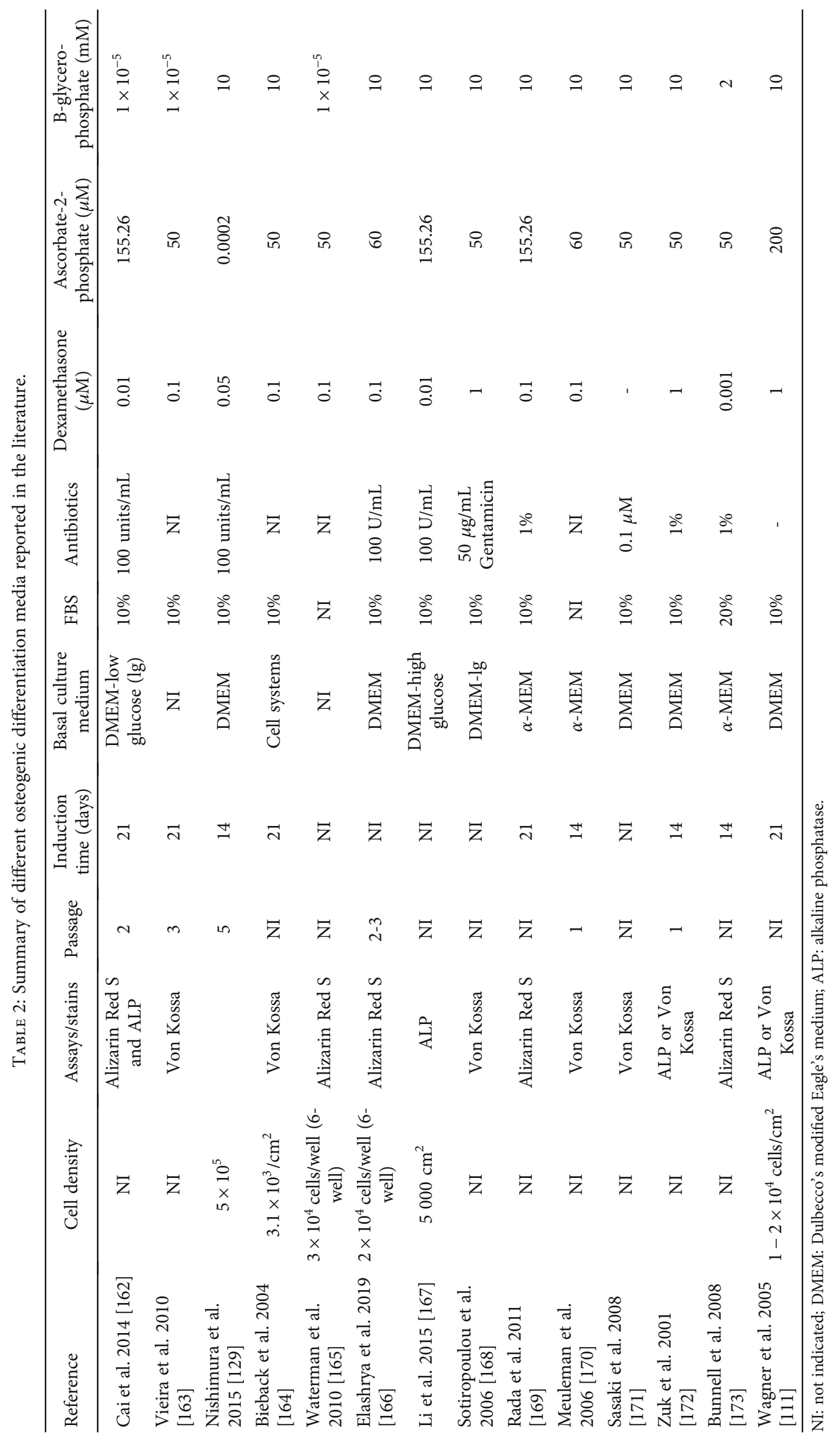


morphology of the cells grown in the xeno-free medium changed much earlier than the cells grown in the FBS induction medium: cell proliferation decreased while cell differentiation increased.

The method of isolation also has an impact on the differentiation capability of MSCs. In a recent study by Walter et al. [180], different isolation techniques from the same donor site were compared with regard to osteo-, adipo-, and chondrogenic differentiation. MSCs isolated from bone marrow aspiration showed better osteogenic differentiation than MSCs generated through outgrowth from culturing bone chips, which can be attributed to the fact that bone marrow aspiration yields more biomaterial and thus more MSCs. Chondrogenic and adipogenic differentiation, both from MSCs from bone marrow aspiration and MSCs generated through outgrowth from culturing bone chips, was relatively low; the authors attribute this to the specific microenvironment of the isolated bone tissue and suggest that this led to MSCs favouring the osteogenic lineage.

Musina et al. [181] compared the osteogenic differentiation potential of MSCs from different tissue sources after a three-week induction period. These investigators reported that BM-MSCs displayed the highest level of osteogenic differentiation, followed by ASCs which showed better osteogenic differentiation capabilities than MSCs isolated from the thymus, skin, and placental tissues. Mohamed-Ahmed et al. [182] compared the osteogenic potential of MSCs isolated from bone marrow and adipose tissue and also reported that BM-MSCs possess enhanced osteogenic potential when compared to ASCs. The reason for the difference was attributed in part to increased alkaline phosphatase (ALP) activity and osteogenic gene expression kinetics. Early-stage osteogenic genes such as RUNX2, collagen type I, and ALP were expressed as early as day 14 in osteogenic differentiating BM-MSCs, while these genes were only expressed on day 21 in differentiating ASCs. This indicates that BM-MSCs stop proliferation early (day 14) and switch to differentiation and formation of a mature collagenous matrix, while ASCs have an extended proliferation period and only switch to differentiation after day 21 , resulting in BM-MSCs having greater mineralization and therefore more bone tissue on day 21 [182]. Shen et al. [153] compared MSCs derived from the amniotic membrane (AM-MSCs), the umbilical cord (UC-MSCs), the chorionic membrane (CM-MSCs), and the decidua (DC-MSCs) and reported enhanced osteogenic differentiation (based on ARS staining and ALP activity) in AM-MSCs and UC-MSCs when compared to CM-MSCs and DC-MSCs. In terms of gene expression profiles involved in osteogenesis, AM-MSCs and UCMSCs showed strongly enhanced expression of Ocn compared to CM-MSCs and DC-MSCs. MSCs from all four sources showed the same expression levels of Osx and collagen type I on day 21. Szöke et al. [183] compared the osteogenic potential of MSCs isolated from bone marrow and adipose tissue. They concluded that although ASCs had a higher proliferative capacity and a greater ability to form a collagenous extracellular matrix, their terminal osteogenic differentiation capability was reduced. BM-MSCs expressed a higher level of the late osteogenic markers Ocn and BSP.
They further went on to suggest that ASCs may be more suitable for in vitro studies, as their isolation procedure is less invasive than BM-MSCs, and although their terminal differentiation capability is reduced, it is still adequate for in vitro studies, while BM-MSCs may hold greater potential for in vivo studies as their terminal osteogenic differentiation capability is greater than that of ASCs. For more information on the differences between BM-MSCs and ASCs with regard to their osteogenic potential, we refer the reader to a review by Liao [184].

Multiple barriers limit the clinical application of MSCs. Many of these are related to the need to extensively expand these cells ex vivo in order to achieve clinically relevant cell numbers. One major barrier associated with extensive ex vivo expansion is the decrease in differentiation potential, mainly due to the loss of telomerase activity, also known as replicative senescence [185]. MSCs tend to lose their differentiation potential as passage number increases, and it is thus important to limit expansion rounds, ideally staying below 5 passages [186, 187]. Bonab et al. [187] reported that MSCs, especially BM-MSCs, show a lower multilineage differential potential due to morphological changes and a decrease in telomere length resulting in the loss of MSC characteristics during long-term culturing. The thawing of MSCs preserved in liquid nitrogen results in a heat-shock response ("cryogenic injury") which leads to a decrease in their immune modulatory function [188]. Another disadvantage of long-term culturing is an increase in the probability of malignant transformation, in which cells acquire cancer-like properties [189].

A further limit to in vitro cell culturing is the use of foetal bovine/calf serum (FBS/FCS) as a supplement to cell culture medium to ensure optimal cell proliferation [190]. Although commonly used, FBS/FCS-supplemented growth media are associated with number of disadvantages. First, FBS/FCS shows batch-to-batch variation due to the variable composition of the product, and thus, results are often not reproducible [191]. Furthermore, FBS/FCS is xenogeneic and contains bovine proteins that can potentially elicit an immune response in humans [192]. The transmission of zoonotic diseases is also a possibility and thus also a primary concern when culturing cells in FBS/FCS; cells that have been cultured in FBS/FCS can therefore not be used clinically [193].

Due to the disadvantages associated with FBS/FCS, the use of human blood products in cell culture medium as alternatives to animal serum is becoming increasingly popular [194, 195]. In short, blood is separated by centrifugation into its components, i.e., platelets, growth factors, and fibrin, which are separated from erythrocytes [196]. Some of these blood products include human serum (HS), platelet-rich plasma (PRP), platelet-poor plasma (PPP), fresh frozen plasma (FFP), and human platelet lysate (HPL). Human serum (HS) is produced by taking whole blood donated from a patient, allowing it to clot and centrifuging the blood to produce serum that is devoid of platelets, erythrocytes, and leukocytes [197]. Plasma is the noncellular liquid part of whole blood. Two human alternatives can be prepared from plasma: PRP and PPP. The difference is the 
concentration of platelets. Platelets are anucleated, discshaped cell fragments that play a role in cell growth, differentiation, and tissue regeneration [198]. When preparing PRP, whole blood is centrifuged, and the supernatant (plasma) is centrifuged again to collect a platelet pellet; the platelet pellet is then resuspended in a smaller volume of plasma thus combining the plasma and buffy coat into one [199]. Alternatively, PRP can be collected via apheresis [200]. PPP is prepared by removing platelets from the plasma obtained from whole blood. Fresh frozen plasma (FFP) is obtained by rapidly freezing plasma separated from whole blood at $-65^{\circ} \mathrm{C}$ [201]. Lastly, to produce HPL, PRP is submitted to several freeze-thaw cycles to rupture the platelets releasing growth factors, followed by centrifugation to remove cell debris [200]. The various human alternatives provide unique advantages and disadvantages with regard to culturing MSCs in in vitro by providing suitable growth factors and ensuring genomic stability [197].

\section{Bone Regeneration and Repair: Clinical Application}

Bone is a vital part of the human body that protects and supports various organs, enables mobility, stores minerals, and produces cells of the hematopoietic lineage [202]. Bone fractures typically heal without the need for major intervention; however, there are more than 2 million cases worldwide in which patients require bone reconstruction using tissue transplants [203]. Current reconstruction procedures involve autologous bone grafts, allogeneic bone grafts, and artificial metal or ceramic replacements.

Autologous bone grafts are viewed as the gold standard for treating bone defects as they enhance osteogenesis and are less likely to be rejected by the host [204]. However, $10 \%$ of bone harvests are associated with major complications, limited supply, and donor-site morbidity [205, 206]. Allogeneic bone grafts provide an ample source of tissue, but the risk of immune rejection and the transmission of diseases make them less ideal [207]. The use of metals as artificial replacements also has limitations such as tissue-host integration, increased risk of infection, and wearing out [208]. The brittle nature of ceramic replacements is especially problematic in areas where high stress or torsion is endured [209]. It is thus clear that alternative, more effective options are needed for the treatment of skeletal defects.

\section{The Use of Cultured MSCs for Osteogenesis In Vivo}

The osteogenic differentiation potential of multipotent MSCs has gained increasing interest in tissue engineering especially when it comes to offering an alternative to overcome the limitations of bone grafts and artificial replacements [210]. Multiple in vitro studies have demonstrated that MSCs are able to differentiate into bone tissue, but bone formation is a complex process that involves many cell types, growth factors, cytokines, and mechanical stimulation that all form part of the environmental niche [211]. Therefore, investigation of bone formation in vivo is required to pro- vide a complete understanding of osteogenesis and also bridges the gap between the use of MSCs in vitro and the clinical use of MSCs for bone repair.

Most studies that have investigated osteogenic differentiation of MSCs in vivo first expanded the cells ex vivo, seeded them onto a scaffold, and transplanted the scaffold subcutaneously in an animal model in which osteogenesis was studied [212-214]. For optimal bone regeneration, the biomaterial used as a scaffold should be biocompatible, cost effective, biodegradable, and should also induce or improve the osteogenic process. The biological behaviour of MSCs is greatly affected by the surface morphology of the biomaterial which in turn affects the formation of bone tissue [215]. The most common scaffold material being used in tissue engineering is hydroxyapatite, an inorganic material that is naturally found in bone tissue [216]. These scaffolds are cast into the desired shape. Another new and attractive method of making scaffolds is the use of 3-dimensional (3D) printing, as it allows for a reproducible design when it comes to pore size [217]. Once the scaffolds are transplanted, MSCs differentiate into osteoblasts and form bone tissue.

Several factors play a role in inducing MSC differentiation into bone in vivo including paracrine signalling pathways in the region of bone injury [218]. When bone injury occurs, perivascular stem cells induce paracrine pathways through the secretion of Wnt-related molecules that in turn activate the BMP and Wnt $\beta$-catenin pathways causing osteogenic differentiation [219]. Furthermore, MSCs create a microenvironment that supports new bone formation through the production of an ECM [220]. Several approaches have been investigated to enhance osteogenic differentiation in vivo including harvesting of ECM to coat biomaterials. The use of ECM not only improves osteogenic differentiation but also enhances MSC survival in vivo [221223]. Another approach is to coat biomaterials with osteogenic inductive compounds [224-226]. MSCs can also be primed or predifferentiated down the osteogenic lineage before seeding them onto scaffolds [227-229]. Lastly, MSCs can be genetically engineered to express bone inducing genes which enhances osteogenic differentiation [230-233].

Several methods, such as histological staining, histomorphometry, immunohistochemistry, and quantitative realtime polymerase chain reaction (RT-qPCR), are used to assess the success of osteogenesis in vivo. Once osteogenesis has been allowed to occur in in vivo mouse models, the scaffolds on which the new bone tissue has formed are resected, and the degree of osteogenesis is measured. Histological staining with haematoxylin and eosin is used to nonspecifically detect newly formed bone matrix [234]. A combination of Alcian blue, haematoxylin, orange $g$, phloxine $b$, and eosin serves as a more specific histological stain for mature bone tissue [235]. Immunohistochemistry allows for the identification of specific antigens such as type I collagen, Ocn, Opn, and BMP-2 [236-238]. Lastly, RT-qPCR can be used to assess the expression of osteogenesis-associated genes such as ALP, RUNX2, BSP, Osx, Ocn, Dlx5, and BMP-2 [213, 239, 240].

Angiogenesis needs to occur for successful bone healing in large bone defects. The successful translation MSC- 
associated cell therapy products for the treatment of bone defects in the clinical setting must be accompanied by rapid vascularization of the implanted scaffold [241]. Vascularization results in adequate delivery of nutrients, oxygen supply, and the removal of waste products. Rapid vascularization also supports the survival of the seeded cells. To promote rapid vascularization, some studies suggest coculturing MSCs and endothelial cells, the latter for their ability to promote angiogenesis [241, 242]. Other studies suggest using a cell type that has the ability to differentiate into both bone tissue and endothelial cells to improve angiogenesis in vivo [213]. Brennan et al. [213] used ASCs based on the assumption that ASCs can differentiate into both endothelial cells and osteoblasts; they found that although ASCs were able to achieve both osteogenesis and angiogenesis; the degree of osteogenesis was inferior to the degree of osteogenesis achieved by BM-MSCs. These investigators then investigated coculturing BM-MSCs and ASCs and found that although there was enhanced blood vessel formation, osteogenesis was not enhanced. Brennan et al. [213] concluded that ASCs need to be osteogenically primed prior to implantation to achieve enhanced osteogenic abilities. The need to prime ASCs to undergo osteogenic differentiation was supported by various other investigators who found that without priming, ASCs fail to heal critical-size defects [243-245]. Another interesting hypothesis was that the immune system and bone formation are linked. Several studies have suggested that MSCs secrete paracrine factors that recruit immune cells to the site of injury leading to bone formation [211, $246,247]$. In order to close the gap between culturing MSCs ex vivo and the clinical use of MSCs for the treatment of bone defects, new methods are required to improve the efficiency of osteogenesis in vivo through, for example, the use growth factors, and by improving methods of cytokine delivery to the implanted scaffold.

\section{The Use of MSC-Derived Exosomes for Osteogenesis In Vivo}

The ability of MSCs to secrete exosomes, in addition to cytokines and growth factors, contributes to their therapeutic effect [248]. Multiple in vivo studies have demonstrated that very few MSCs engraft at sites of injury when administered intravenously, but rather are filtered out in the lungs; however, they still exhibit a therapeutic effect [249-253]. Other studies have gone on to report that it is in particular the microvesicles/exosomes secreted from MSCs than provide this therapeutic effect $[127,254,255]$. The therapeutic effect of MSC-derived exosomes has been extensively studied in vivo in a wide range of disease models. Some of these include cardiovascular disease [256-258], renal disease [259-261], neurological complications [262-264], pulmonary disease [265-267], wound healing [268, 269], muscle regeneration [270], and many more. With regard to osteogenesis, multiple studies have shown that MSC-derived exosomes can stimulate the osteogenic differentiation process, increasing bone regeneration. Qi et al. [271] demonstrated that exosomes from BM-MSCs from ovariectomized rats stimulated osteogenesis and were able to regenerate bone tis- sue in a critical-sized calvarial defect. They also found that the increase in osteogenic stimulation was related to the increase in exosome concentration over time. The repair of a critical osteochondral defect in adult immunocompromised rats through the intravenous injection of human embryonic MSC-derived exosomes was demonstrated by Zhang et al. [272]. The use of MSC-derived exosomes in regenerative medicine has gained a great deal of attention as it is an attractive alternative to using MSCs. MSCderived exosomes are cell-free and are more compatible with a variety of administration routes [272]. Another reason why exosomes are attractive is that they lack major histocompatibility complex (MHC) I/II proteins, and there is therefore no need for immunosuppression [273, 274].

\section{Therapeutic Use of MSCs for Bone Diseases}

Bone remodelling is a complex and highly integrated process, and as described in this review, it involves various transcription factors and osteogenic genes and their protein products including cytokines, growth factors, and extracellular matrix components. The smallest deviations from this well-balanced system can affect bone health and lead to a number of bone diseases. Bone tissue is a porous, meshlike network made up of collagen proteins and calcium phosphate minerals and is constantly being replaced throughout life. When the bone remodelling process is defective, this mesh-like structure becomes porous as seen in osteoporosis, leading to brittle bones and fractures.

According to the International Osteoporosis Foundation, over 200 million people are affected by osteoporosis worldwide [275]. Osteoporosis is associated with low bone mass as well as bone deterioration usually seen with increasing age, and it is thought that osteoporosis results, in part, from a significant decrease in the number of MSCs present in the bone marrow, leading to less new bone formation [276]. Osteoporosis is currently treated with drugs that increase bone resorption, but these drugs are associated with multiple adverse effects [277]. Stem cell therapy is a potential alternative for the treatment of osteoporosis, reducing the susceptibility to fractures by increasing the MSC pool present within the bone marrow. Wang et al. [278] reported increased bone formation, trabecular thickness, and overall strength of bone tissue by embedding MSCs into the distal femurs of osteoporotic rabbits. Hsiao et al. [279] treated osteoporotic mice by injecting MSCs intravenously. They observed that the MSCs homed to the bone marrow where they increased bone density, rescuing the mice from osteoporosis.

$\mathrm{OA}$ is a degenerative joint disease affecting synovial joints and frequently results in chronic pain [280]. Currently, the treatment of $\mathrm{OA}$ involves long-term pain management with the use of pharmacological therapies. Osteotomy can improve alignment, but this therapy is limited as it can decrease the risk of OA but has little effect on degeneration once it has occurred [281]. It has been hypothesized that the multipotency properties of MSCs could also benefit patients with OA. Currently, there are 102 documented clinical trials assessing the potential of MSCs for 
the treatment of OA; however, more preclinical work is needed to fully understand the mechanisms behind the potential healing effect of MSCs in OA [280]. Eder et al. [282] comprehensively reviewed the use of both ASCs and BM-MSCs in the treatment of musculoskeletal disorders, including OA. The overall conclusion of these studies is that the use of MSCs (ASCs and BM-MSCs) decreases pain levels and improves healing rates. Eder et al. [282] concluded that MSCs could be used as a therapeutic option in the future treatment of OA, although the field would benefit from large, randomized, blinded clinical investigations.

The repair and reconstruction of large segments of bone, such as fractures displaying nonunion or delayed union, and large bone defects, have been a challenge to orthopaedic surgery. MSCs are an attractive therapeutic option for the healing of bone defects due to their ability in vivo to influence the secretion of specific factors by the immune system and through their interaction with other cells [283]. A number of clinical trials have been conducted with the aim of assessing the ability of MSCs to improve fracture healing. In most cases, improved fracture healing rates, decreased pain levels, and improved remodelling have been observed when compared to controls [284-291]. The conclusions that can be drawn from these studies indicate that the use of MSCs could be an important treatment option for larger more difficult bone defects in the future. Many more bone diseases could benefit from bone regeneration therapy and hence the importance of understanding the osteogenic process in full.

\section{Conclusions}

The multipotent differentiation and secretory capabilities of MSCs makes them attractive for transplantation and regenerative therapies particularly in treating bone defects/disorders. MSCs can successfully differentiate into osteoblasts in vitro, and multiple studies in this setting have provided methods to improve the differentiation process. MSCs can also be transduced effectively to express genes of interest that can further improve osteogenesis in vitro, and it is likely that this will be maintained in vivo. In an in vivo setting, cultured MSCs retain their ability to differentiate into osteoblasts. The transcriptional regulation of osteogenesis has not been fully elucidated. Further understanding of bone biology will rely on deciphering the complex regulatory network and multiple interactions between regulatory factors. The lack of cell-culturing systems that fully replicate osteogenic differentiation in vivo has made the understanding of transcriptional regulators that control osteogenesis difficult. It is however important to ensure the safe and effective use of MSCs in the therapeutic setting. Therefore, more in vivo studies are needed to address the numerous in vitro discrepancies. The use of MSCs in the clinical setting awaits final validation, but there are multiple ongoing clinical trials that show promising results. Fundamental questions regarding the biology of osteogenesis remain, and the therapeutic potential of MSCs needs to be fully explored before they can be used as a routine treatment option. The field is none- theless highly promising, and important contributions to the practice of medicine can be expected.

\section{Conflicts of Interest}

The authors have no conflicts of interest to declare.

\section{Acknowledgments}

This work was supported by the South African Medical Research Council (Extramural Unit for Stem Cell Research and Therapy) (MSP), the University of Pretoria via the Institute for Cellular and Molecular Medicine of (MSP), and a postgraduate student bursary (JM).

\section{References}

[1] X. Wei, X. Yang, Z. Han, F. Qu, L. Shao, and Y. Shi, "Mesenchymal stem cells: a new trend for cell therapy," Acta Pharmacologica Sinica, vol. 34, no. 6, pp. 747-754, 2013.

[2] R. Langer and J. P. Vacanti, “Tissue engineering," Science, vol. 260, no. 5110, pp. 920-926, 1993.

[3] F. Granero-molto, J. A. Weis, L. Longobardi et al., "Role of mesenchymal stem cells in regenerative medicine: application to bone and cartilage repair," Expert opinion on biological therapy, vol. 8, no. 3, pp. 255-268, 2008.

[4] G. M. Calori, E. L. Mazza, S. Mazzola et al., "Non-unions," Clinical Cases in Mineral and Bone Metabolism, vol. 14, no. 2, pp. 186-188, 2017.

[5] V. Bunpetch, Z. Zhang, X. Zhang et al., Strategies for MSC Expansion and MSC-Based Microtissue for Bone Regeneration, Elsevier B.V., 2017.

[6] G. Karsenty and E. F. Wagner, "Reaching a genetic and molecular understanding of skeletal development," Developmental cell, vol. 2, no. 4, pp. 389-406, 2002.

[7] J. Caetano-Lopes, H. Canhão, and J. Fonseca, "Osteoblasts and bone formation," Acta reumatológica portuguesa, vol. 5, pp. 103-110, 1998.

[8] P. J. Marie, O. Fromigué, and D. Modrowski, Deregulation of Osteoblast Differentiation in Primary Bone Cancers, vol. 15Elsevier Inc., Second Edi edition, 2015.

[9] Y. Han, X. You, W. Xing, Z. Zhang, and W. Zou, "Paracrine and endocrine actions of bone-the functions of secretory proteins from osteoblasts, osteocytes, and osteoclasts," Bone research, vol. 6, no. 1, p. 16, 2018.

[10] J. S. Kenkre and J. H. D. Bassett, "The bone remodelling cycle," Annals of clinical biochemistry, vol. 55, no. 3, pp. 308-327, 2018.

[11] D.-H. Yang and M.-Y. Yang, "The role of macrophage in the pathogenesis of osteoporosis," International journal of molecular sciences, vol. 20, no. 9, p. 2093, 2019.

[12] C. Wittkowske, G. C. Reilly, D. Lacroix, and C. M. Perrault, "In vitro bone cell models: impact of fluid shear stress on bone formation," Frontiers in Bioengineering and Biotechnology, vol. 4, 2016.

[13] S. L. Teitelbaum, "Bone resorption by osteoclasts," Science, vol. 289, no. 5484, pp. 1504-1508, 2000.

[14] L. Zheng, Q. Tu, S. Meng et al., "Runx2/DICER/miRNA pathway in regulating osteogenesis," Journal of cellular physiology, vol. 232, no. 1, pp. 182-191, 2017. 
[15] M. Bruderer, R. G. Richards, M. Alini, and M. J. Stoddart, "Role and regulation of RUNX2 in osteogenesis," European Cells \& Materials, vol. 28, pp. 269-286, 2014.

[16] X. Zhang, M. Yang, L. Lin et al., "Runx2 overexpression enhances osteoblastic differentiation and mineralization in adipose - derived stem cells in vitro and in vivo," Calcified tissue international, vol. 79, no. 3, pp. 169-178, 2006.

[17] C. Haxaire, E. Haÿ, and V. Geoffroy, "Runx2 controls bone resorption through the down-regulation of the Wnt pathway in osteoblasts," The American journal of pathology, vol. 186, no. 6, pp. 1598-1609, 2016.

[18] K. Thirunavukkarasu, D. L. Halladay, R. R. Miles et al., “The Osteoblast-specific Transcription Factor Cbfal Contributes to the Expression of Osteoprotegerin, a Potent Inhibitor of Osteoclast Differentiation and Function," Journal of Biological Chemistry, vol. 275, no. 33, pp. 25163-25172, 2000.

[19] F. Otto, A. P. Thornell, T. Crompton et al., "Cbfa1, a candidate gene for cleidocranial dysplasia syndrome, is essential for osteoblast differentiation and bone development," Cell, vol. 89, no. 5, pp. 765-771, 1997.

[20] D. Mitra, "Runx2 activity in committed osteoblasts is not essential for embryonic skeletogenesis," Connective tissue research, vol. 55, pp. 1-7, 2014.

[21] S. L. Cheng, J. S. Shao, N. Charlton-Kachigian, A. P. Loewy, and D. A. Towler, "Msx2 Promotes Osteogenesis and Suppresses Adipogenic Differentiation of Multipotent Mesenchymal Progenitors," Journal of Biological Chemistry, vol. 278, no. 46, pp. 45969-45977, 2003.

[22] D. M. Willis, A. P. Loewy, N. Charlton-Kachigian, J. S. Shao, D. M. Ornitz, and D. A. Towler, "Regulation of Osteocalcin Gene Expression by a Novel Ku Antigen Transcription Factor Complex," Journal of Biological Chemistry, vol. 277, no. 40, pp. 37280-37291, 2002.

[23] I. Satokata, L. Ma, H. Ohshima et al., "Msx2 deficiency in mice causes pleiotropic defects in bone growth and ectodermal organ formation," Nature genetics, vol. 24, no. 4, pp. 391-395, 2000.

[24] C. J. Rosen, L. R. Donahue, and S. J. Hunter, "Insulin-like growth factors and bone: the osteoporosis connection," Proceedings of the Society for Experimental Biology and Medicine, vol. 206, no. 2, pp. 83-102, 1994.

[25] J. M. Lean, A. G. Mackay, J. W. Chow, and T. J. Chambers, "Osteocytic expression of mRNA for c-fos and IGF-I: an immediate early gene response to an osteogenic stimulus," American Journal of Physiology-Endocrinology and Metabolism, vol. 270, no. 6, pp. E937-E945, 1996.

[26] M. H. C. Sheng, X. D. Zhou, L. F. Bonewald, D. J. Baylink, and K. H. W. Lau, "Disruption of the insulin-like growth factor-1 gene in osteocytes impairs developmental bone growth in mice," Bone, vol. 52, no. 1, pp. 133-144, 2013.

[27] M. Zhang, S. Xuan, M. L. Bouxsein et al., "Osteoblast-specific Knockout of the Insulin-like Growth Factor (IGF) Receptor Gene Reveals an Essential Role of IGF Signaling in Bone Matrix Mineralization," Journal of Biological Chemistry, vol. 277, no. 46, pp. 44005-44012, 2002.

[28] S. Mohan, C. Richman, R. Guo et al., "Insulin-like growth factor regulates peak bone mineral density in mice by both growth hormone-dependent and -independent mechanisms," Endocrinology, vol. 144, no. 3, pp. 929-936, 2003.
[29] W. Wang, N. Lian, Y. Ma et al., "Chondrocytic Atf4 regulates osteoblast differentiation and function via Ihh," Development, vol. 139, no. 3, pp. 601-611, 2012.

[30] W. Wang, N. Lian, L. Li et al., "Atf4 regulates chondrocyte proliferation and differentiation during endochondral ossification by activating Ihh transcription," Development, vol. 136, no. 24, pp. 4143-4153, 2009.

[31] T. Matsubara, K. Kida, A. Yamaguchi et al., "BMP2 Regulates Osterix through Msx2 and Runx2 during Osteoblast Differentiation," Journal of biological chemistry, vol. 283, no. 43, pp. 29119-29125, 2008.

[32] Y. Han, C. Y. Kim, H. Cheong, and K. Y. Lee, "Osterix represses adipogenesis by negatively regulating $\operatorname{PPAR} \gamma$ transcriptional activity," Scientific reports, vol. 6, no. 1, article 35655, pp. 1-11, 2016.

[33] M. J. Hilton, X. Tu, X. Wu et al., "Notch signaling maintains bone marrow mesenchymal progenitors by suppressing osteoblast differentiation," Nature medicine, vol. 14, no. 3, pp. 306-314, 2008.

[34] A. B. Celil and P. G. Campbell, "BMP-2 and Insulin-like Growth Factor-I Mediate Osterix (Osx) Expression in Human Mesenchymal Stem Cells via the MAPK and Protein Kinase D Signaling Pathways," Journal of Biological Chemistry, vol. 280, no. 36, pp. 31353-31359, 2005.

[35] S. Kang, C. N. Bennett, I. Gerin, L. A. Rapp, K. D. Hankenson, and O. A. Macdougald, "Wnt Signaling Stimulates Osteoblastogenesis of Mesenchymal Precursors by Suppressing CCAAT/Enhancer-binding Protein $\alpha$ and Peroxisome Proliferator- activated Receptor $\gamma$," Journal of Biological Chemistry, vol. 282, no. 19, pp. 14515-14524, 2007.

[36] R. S. Siffert, "The role of alkaline PHOSPHATASE in osteogenesis," The Journal of experimental medicine, vol. 93, no. 5, pp. 415-426, 1951.

[37] T. Nakamura, A. Nakamura-Takahashi, M. Kasahara, A. Yamaguchi, and T. Azuma, "Tissue-nonspecific alkaline phosphatase promotes the osteogenic differentiation of osteoprogenitor cells," Biochemical and biophysical research communications, vol. 524, no. 3, pp. 702-709, 2020.

[38] S. Narisawa, M. C. Yadav, and J. L. Millán, "In vivo overexpression of tissue-nonspecific alkaline phosphatase increases skeletal mineralization and affects the phosphorylation status of osteopontin," Journal of bone and mineral research, vol. 28, no. 7, pp. 1587-1598, 2013.

[39] S. Narisawa, N. Fröhlander, and J. L. Millán, "Inactivation of two mouse alkaline phosphatase genes and establishment of a model of infantile hypophosphatasia," Developmental dynamics: an official publication of the American Association of Anatomists, vol. 208, no. 3, pp. 432-446, 1997.

[40] K. G. Waymire, J. D. Mahuren, J. M. Jaje, T. R. Guilarte, S. P. Coburn, and G. R. MacGregor, "Mice lacking tissue nonspecific alkaline phosphatase die from seizures due to defective metabolism of vitamin B-6," Nature genetics, vol. 11, no. 1, pp. 45-51, 1995.

[41] W. Liu, L. Zhang, K. Xuan et al., "Alkaline phosphatase controls lineage switching of mesenchymal stem cells by regulating the lrp6/gsk $3 \beta$ complex in hypophosphatasia," Theranostics, vol. 8, no. 20, pp. 5575-5592, 2018.

[42] A. Nakamura-Takahashi, K. Miyake, A. Watanabe et al., "Treatment of hypophosphatasia by muscle-directed expression of bone-targeted alkaline phosphatase via selfcomplementary AAV8 vector," Molecular Therapy-Methods \& Clinical Development, vol. 3, article 15059, 2016. 
[43] E. G. Canty and K. E. Kadler, "Procollagen trafficking, processing and fibrillogenesis," Journal of cell science, vol. 118, no. 7, pp. 1341-1353, 2005.

[44] A. I. Alford, K. M. Kozloff, and K. D. Hankenson, "Extracellular matrix networks in bone remodeling," The international journal of biochemistry \& cell biology, vol. 65, pp. 20-31, 2015.

[45] Q. Chen, P. Shou, L. Zhang et al., “An osteopontin-integrin interaction plays a critical role in directing adipogenesis and osteogenesis by mesenchymal stem cells," Stem Cells, vol. 32, no. 2, pp. 327-337, 2014.

[46] H. Ryoo, M. Lee, and Y. Kim, "Critical molecular switches involved in BMP-2-induced osteogenic differentiation of mesenchymal cells," Gene, vol. 366, no. 1, pp. 51-57, 2006.

[47] M. Lee, Y. Kim, H. Kim et al., "BMP-2-induced Runx2 Expression Is Mediated by Dlx5, and TGF- $\beta 1$ Opposes the BMP-2-induced Osteoblast Differentiation by Suppression of Dlx5 Expression," Journal of Biological Chemistry, vol. 278, no. 36, pp. 34387-34394, 2003.

[48] N. Samee, V. Geoffroy, C. Marty et al., "Dlx5, a Positive Regulator of Osteoblastogenesis, is Essential for OsteoblastOsteoclast Coupling," The American journal of pathology, vol. 173, no. 3, pp. 773-780, 2008.

[49] D. Acampora, G. R. Merlo, L. Paleari et al., "Craniofacial, vestibular and bone defects in mice lacking the distal-less-related gene Dlx5," Development, vol. 126, no. 17, pp. 3795-3809, 1999.

[50] R. F. Robledo, L. Rajan, X. Li, and T. Lufkin, "The Dlx5 and Dlx6 homeobox genes are essential for craniofacial, axial, and appendicular skeletal development," Genes \& development, vol. 16, no. 9, pp. 1089-1101, 2002.

[51] A. Muraglia, M. Perera, S. Verardo et al., "DLX5 overexpression impairs osteogenic differentiation of human bone marrow stromal cells," European journal of cell biology, vol. 87, no. 10, pp. 751-761, 2008.

[52] P. Collin-Osdoby, L. Rothe, F. Anderson, M. Nelson, W. Maloney, and P. Osdoby, "Receptor Activator of NF- $\kappa$ B and Osteoprotegerin Expression by Human Microvascular Endothelial Cells, Regulation by Inflammatory Cytokines, and Role in Human Osteoclastogenesis," Journal of Biological Chemistry, vol. 276, no. 23, pp. 20659-20672, 2001.

[53] K. Oshita, K. Yamaoka, N. Udagawa et al., "Human mesenchymal stem cells inhibit osteoclastogenesis through osteoprotegerin production," Arthritis \& Rheumatism, vol. 63, no. 6, pp. 1658-1667, 2011.

[54] H. Min, S. Morony, I. Sarosi et al., "Osteoprotegerin reverses osteoporosis by inhibiting endosteal osteoclasts and prevents vascular calcification by blocking a process resembling osteoclastogenesis," Journal of Experimental Medicine, vol. 192, no. 4, pp. 463-474, 2000.

[55] A. Mizuno, N. Amizuka, K. Irie et al., "Severe osteoporosis in mice lacking osteoclastogenesis inhibitory factor/osteoprotegerin," Biochemical and biophysical research communications, vol. 247, no. 3, pp. 610-615, 1998.

[56] S. Palumbo and W. J. Li, "Osteoprotegerin enhances osteogenesis of human mesenchymal stem cells," Tissue Engineering Part A, vol. 19, no. 19-20, pp. 2176-2187, 2013.

[57] Y. Liu, H. Du, Y. Wang et al., "Osteoprotegerin-Knockout Mice Developed Early Onset Root Resorption," Journal of endodontics, vol. 42, no. 10, pp. 1516-1522, 2016.

[58] M. L. Zoch, T. L. Clemens, and R. C. Riddle, "New insights into the biology of osteocalcin," Bone, vol. 82, pp. 42-49, 2016.
[59] J. K. Chen, H. S. Shapiro, J. L. Wrana, S. Reimers, J. N. Heersche, and J. Sodek, "Localization of bone sialoprotein (BSP) expression to sites of mineralized tissue formation in fetal rat tissues by in situ hybridization," Matrix, vol. 11, no. 2, pp. 133-143, 1991.

[60] G. K. Hunter and H. A. Goldberg, "Nucleation of hydroxyapatite by bone sialoprotein," Proceedings of the National Academy of Sciences, vol. 90, no. 18, pp. 8562-8565, 1993.

[61] J. A. R. Gordon, C. E. Tye, A. V. Sampaio, T. M. Underhill, G. K. Hunter, and H. A. Goldberg, "Bone sialoprotein expression enhances osteoblast differentiation and matrix mineralization in vitro," Bone, vol. 41, no. 3, pp. 462-473, 2007.

[62] G. Bouet, W. Bouleftour, L. Juignet et al., "The impairment of osteogenesis in bone sialoprotein (BSP) knockout calvaria cell cultures is cell density dependent," PLoS One, vol. 10, no. 2, article e0117402, 2015.

[63] W. Bouleftour, M. Boudiffa, N. M. Wade-Gueye et al., "Skeletal development of mice lacking bone sialoprotein (BSP)impairment of long bone growth and progressive establishment of high trabecular bone mass," PLoS One, vol. 9, no. 5, article e95144, 2014.

[64] L. Malaval, N«. M.. Wade-Guéye, M. Boudiffa et al., "Bone sialoprotein plays a functional role in bone formation and osteoclastogenesis," The Journal of experimental medicine, vol. 205, no. 5, pp. 1145-1153, 2008.

[65] S. Thysen, F. Cailotto, and R. Lories, "Osteogenesis induced by frizzled-related protein (FRZB) is linked to the netrinlike domain," Laboratory Investigation, vol. 96, no. 5, pp. 570-580, 2016.

[66] R. J. U. Lories, J. Peeters, A. Bakker et al., “Articular cartilage and biomechanical properties of the long bones in Frzbknockout mice," Arthritis \& Rheumatism: Official Journal of the American College of Rheumatology, vol. 56, no. 12, pp. 4095-4103, 2007.

[67] B. T. MacDonald, D. M. Joiner, S. M. Oyserman et al., "Bone mass is inversely proportional to Dkk1 levels in mice," Bone, vol. 41, no. 3, pp. 331-339, 2007.

[68] X. Li, P. Liu, W. Liu et al., "Dkk2 has a role in terminal osteoblast differentiation and mineralized matrix formation," Nature genetics, vol. 37, no. 9, pp. 945-952, 2005.

[69] R. Gao, L. Zhan, C. Meng et al., "Homeobox B7 promotes the osteogenic differentiation potential of mesenchymal stem cells by activating RUNX2 and transcript of BSP," International journal of clinical and experimental medicine, vol. 8, no. 7, pp. 10459-10470, 2015.

[70] R. P. Gersch, F. Lombardo, S. C. McGovern, and M. Hadjiargyrou, "Reactivation of Hox gene expression during bone regeneration," Journal of orthopaedic research, vol. 23, no. 4, pp. 882-890, 2005.

[71] S. Z. Bathaie, N. Faridi, A. Nasimian, H. Heidarzadeh, and F. Tamanoi, How Phytochemicals Prevent Chemical Carcinogens and/or Suppress Tumor Growth?, vol. 37Elsevier Inc., 1st ed edition, 2015.

[72] T. F. Day, X. Guo, L. Garrett-Beal, and Y. Yang, "Wnt/ $\beta$ catenin signaling in mesenchymal progenitors controls osteoblast and chondrocyte differentiation during vertebrate skeletogenesis," Developmental cell, vol. 8, no. 5, pp. 739-750, 2005.

[73] W. Qiu, T. E. Andersen, J. Bollerslev, S. Mandrup, B. M. Abdallah, and M. Kassem, "Patients with high bone mass phenotype exhibit enhanced osteoblast differentiation and 
inhibition of adipogenesis of human mesenchymal stem cells," Journal of Bone and Mineral Research, vol. 22, no. 11, pp. 1720-1731, 2007.

[74] G. Rawadi, B. Vayssière, F. Dunn, R. Baron, and S. RomanRoman, "BMP-2 controls alkaline phosphatase expression and osteoblast mineralization by a Wnt autocrine loop," Journal of Bone and Mineral Research, vol. 18, no. 10, pp. 18421853, 2003.

[75] T. P. Hill, D. Später, M. M. Taketo, W. Birchmeier, and C. Hartmann, "Canonical Wnt $/ \beta$-catenin signaling prevents osteoblasts from differentiating into chondrocytes," Developmental cell, vol. 8, no. 5, pp. 727-738, 2005.

[76] Y.-D. Cho, W.-J. Kim, W.-J. Yoon et al., "Wnt3a stimulates Mepe, matrix extracellular phosphoglycoprotein, expression directly by the activation of the canonical Wnt signaling pathway and indirectly through the stimulation of autocrine Bmp-2 expression," Journal of cellular physiology, vol. 227, no. 6, pp. 2287-2296, 2012.

[77] Y. Li, J. Yuan, E. Rothzerg et al., "Molecular structure and the role of high-temperature requirement protein 1 in skeletal disorders and cancers," Cell proliferation, vol. 53, no. 2, article e12746, 2020.

[78] M. Kawai, A. C. Breggia, V. E. Demambro et al., "The Heparin-binding Domain of IGFBP-2 Has Insulin-like Growth Factor Binding-independent Biologic Activity in the Growing Skeleton," Journal of Biological Chemistry, vol. 286, no. 16, pp. 14670-14680, 2011.

[79] A. Rauch, A. K. Haakonsson, J. G. S. Madsen et al., “Osteogenesis depends on commissioning of a network of stem cell transcription factors that act as repressors of adipogenesis," Nature genetics, vol. 51, no. 4, pp. 716-727, 2019.

[80] E. M. Rosset and A. D. Bradshaw, "SPARC/osteonectin in mineralized tissue," Matrix Biology, vol. 52-54, pp. 78-87, 2016.

[81] K. Tanaka, H. Kaji, T. Yamaguchi et al., "Involvement of the osteoinductive factors, Tmem 119 and BMP-2, and the ER stress response PERK-eIF2 $\alpha$-ATF4 pathway in the commitment of myoblastic into osteoblastic cells," Calcified tissue international, vol. 94, no. 4, pp. 454-464, 2014.

[82] D. Olvera, R. Stolzenfeld, J. C. Marini, M. S. Caird, and K. M. Kozloff, "Low dose of bisphosphonate enhances sclerostin antibody-induced trabecular bone mass gains in Brtl/+ osteogenesis imperfecta mouse model," Journal of Bone and Mineral Research, vol. 33, no. 7, pp. 1272-1282, 2018.

[83] F. M. Lampert, C. Kütscher, G. Stark, and G. Finkenzeller, "Overexpression of Hif- $1 \alpha$ in mesenchymal stem cells Affects Cell-Autonomous Angiogenic and Osteogenic Parameters," Journal of cellular biochemistry, vol. 117, no. 3, pp. 760-768, 2016.

[84] X. Cao and D. Chen, "The BMP signaling and in vivo bone formation," Gene, vol. 357, no. 1, pp. 1-8, 2005.

[85] E. Tsialogiannis, I. Polyzois, Q. O. Tang et al., “Targeting bone morphogenetic protein antagonists: in vitro and in vivo evidence of their role in bone metabolism," Expert opinion on therapeutic targets, vol. 13, no. 1, pp. 123-137, 2009.

[86] D. B. Asserson, H. Orbay, and D. E. Sahar, "Review of the pathways involved in the osteogenic differentiation of adipose-derived stem cells," Journal of Craniofacial Surgery, vol. 30, no. 3, pp. 703-708, 2019.

[87] M. Fujii, K. Takeda, T. Imamura et al., "Roles of bone morphogenetic protein type I receptors and Smad proteins in osteoblast and chondroblast differentiation," Molecular biology of the cell, vol. 10, no. 11, pp. 3801-3813, 1999.

[88] X. Wu, Y. Li, A. Schneider et al., "Impaired osteoblastic differentiation, reduced bone formation, and severe osteoporosis in noggin-overexpressing mice," The Journal of clinical investigation, vol. 112, no. 6, pp. 924-934, 2003.

[89] J. Groppe, J. Greenwald, E. Wiater et al., "Structural basis of BMP signalling inhibition by the cystine knot protein Noggin," Nature, vol. 420, no. 6916, pp. 636-642, 2002.

[90] C. Chen, H. Uludağ, Z. Wang, and H. Jiang, "Noggin suppression decreases BMP-2-induced osteogenesis of human bone marrow-derived mesenchymal stem cells In Vitro," Journal of cellular biochemistry, vol. 113, no. 12, pp. 36723680, 2012.

[91] A. M. Makhdom and R. C. Hamdy, "The role of growth factors on acceleration of bone regeneration during distraction osteogenesis," Tissue Engineering Part B: Reviews, vol. 19, no. 5, pp. 442-453, 2013.

[92] C. Wang, F. Xiao, Y. Gan et al., "Improving bone regeneration using chordin siRNA delivered by $\mathrm{pH}$-responsive and non-toxic polyspermine Imidazole-4,5-Imine," Cellular Physiology and Biochemistry, vol. 46, no. 1, pp. 133-147, 2018.

[93] L. Dudarić, S. Z. Cvek, O. Cvijanović et al., "Expression of the BMP-2, -4 and-7 and their antagonists gremlin, chordin, noggin and follistatin during ectopic osteogenesis," Collegium antropologicum, vol. 37, no. 4, pp. 1291-1298, 2013.

[94] D. Zhang, C. M. Ferguson, R. J. O'Keefe, J. E. Puzas, R. N. Rosier, and P. R. Reynolds, "A role for the BMP antagonist chordin in endochondral ossification," Journal of Bone and Mineral Research, vol. 17, no. 2, pp. 293-300, 2002.

[95] K. Hu, H. Sun, B. Gui, and C. Sui, "Gremlin-1 suppression increases BMP-2-induced osteogenesis of human mesenchymal stem cells," Molecular medicine reports, vol. 15, no. 4, pp. 2186-2194, 2017.

[96] S. C. Rowan, H. Jahns, L. Mthunzi et al., "Gremlin 1 depletion in vivo causes severe enteropathy and bone marrow failure," The Journal of pathology, vol. 251, no. 2, pp. 117-122, 2020.

[97] J. Luo, M. Tang, J. Huang et al., "TGF $\beta / B M P$ Type I Receptors ALK1 and ALK2 Are Essential for BMP9-induced Osteogenic Signaling in Mesenchymal Stem Cells," Journal of Biological Chemistry, vol. 285, no. 38, pp. 29588-29598, 2010.

[98] J. H. Wang, Y. Z. Liu, L. J. Yin et al., "BMP9 and COX-2 form an important regulatory loop in BMP9-induced osteogenic differentiation of mesenchymal stem cells," Bone, vol. 57, no. 1, pp. 311-321, 2013.

[99] C. Xie, X. Ming, Q. Wang et al., "COX-2 from the injury milieu is critical for the initiation of periosteal progenitor cell mediated bone healing," Bone, vol. 43, no. 6, pp. 1075-1083, 2008.

[100] R. Rice, D. P. C. Rice, B. R. Olsen, and I. Thesleff, "Progression of calvarial bone development requires Foxc1 regulation of Msx2 and Alx4," Developmental biology, vol. 262, no. 1, pp. 75-87, 2003.

[101] T. Kume, K. Y. Deng, V. Winfrey, D. B. Gould, M. A. Walter, and B. L. M. Hogan, "The Forkhead/Winged Helix Gene Mf1 Is Disrupted in the Pleiotropic Mouse Mutation congenital hydrocephalus," Cell, vol. 93, no. 6, pp. 985-996, 1998.

[102] F. Mirzayans, R. Lavy, J. Penner-Chea, and F. B. Berry, "Initiation of early osteoblast differentiation events through the direct transcriptional regulation of Msx2 by FOXC1," PLoS One, vol. 7, no. 11, article e49095, 2012. 
[103] A. Hopkins, F. Mirzayans, and F. Berry, "Foxc1 expression in early osteogenic differentiation is regulated by BMP4-SMAD activity," Journal of cellular biochemistry, vol. 117, no. 7, pp. 1707-1717, 2016.

[104] C. M. Karner and F. Long, "Wnt signaling and cellular metabolism in osteoblasts," Cellular and Molecular Life Sciences, vol. 74, no. 9, pp. 1649-1657, 2017.

[105] R. C. Riddle, C. R. Diegel, J. M. Leslie et al., "Lrp5 and Lrp6 exert overlapping functions in osteoblasts during postnatal bone acquisition," PLoS One, vol. 8, no. 5, article e63323, 2013.

[106] C. M. Laine, K. S. Joeng, P. M. Campeau et al., "WNT1 mutations in early-onset osteoporosis and osteogenesis imperfecta," New England Journal of Medicine, vol. 368, no. 19, pp. 1809-1816, 2013.

[107] H. F. Zheng, J. H. Tobias, E. Duncan et al., “WNT16 influences bone mineral density, cortical bone thickness, bone strength, and osteoporotic fracture risk," PLoS genetics, vol. 8, no. 7, article e1002745, p. e1002745, 2012.

[108] V. Deregowski, E. Gazzerro, L. Priest, S. Rydziel, and E. Canalis, "Notch 1 Overexpression Inhibits Osteoblastogenesis by Suppressing Wnt/ $\beta$-Catenin but Not Bone Morphogenetic Protein Signaling," Journal of Biological Chemistry, vol. 281, no. 10, pp. 6203-6210, 2006.

[109] E. M. Horwitz, K. le Blanc, M. Dominici et al., "Clarification of the nomenclature for MSC: the International Society for Cellular Therapy position statement," Cytotherapy, vol. 7, no. 5, pp. 393-395, 2005.

[110] M. F. Pittenger, A. M. Mackay, S. C. Beck et al., "Multilineage potential of adult human mesenchymal stem cells," Science, vol. 284, no. 5411, pp. 143-147, 1999.

[111] W. Wagner, F. Wein, A. Seckinger et al., "Comparative characteristics of mesenchymal stem cells from human bone marrow, adipose tissue, and umbilical cord blood," Experimental hematology, vol. 33, no. 11, pp. 1402-1416, 2005.

[112] J. Cai, W. Li, H. Su et al., "Generation of Human Induced Pluripotent Stem Cells from Umbilical Cord Matrix and Amniotic Membrane Mesenchymal Cells," Journal of Biological Chemistry, vol. 285, no. 15, pp. 11227-11234, 2010.

[113] P. S. in 't Anker, S. A. Scherjon, C. Kleijburg-van der Keur et al., "Amniotic fluid as a novel source of mesenchymal stem cells for therapeutic transplantation," Blood, vol. 102, no. 4, pp. 1548-1549, 2003.

[114] C. M. Raynaud, M. Maleki, R. Lis et al., "Comprehensive characterization of mesenchymal stem cells from human placenta and fetal membrane and their response to osteoactivin stimulation," Stem cells international, vol. 2012, Article ID 658356, 13 pages, 2012.

[115] K. Kita, G. G. Gauglitz, T. T. Phan, D. N. Herndon, and M. G. Jeschke, "Isolation and characterization of mesenchymal stem cells from the sub-amniotic human umbilical cord lining membrane," Stem cells and development, vol. 19, no. 4, pp. 491-502, 2010.

[116] A. N. Schüring, N. Schulte, R. Kelsch, A. Röpke, L. Kiesel, and M. Götte, "Characterization of endometrial mesenchymal stemlike cells obtained by endometrial biopsy during routine diagnostics," Fertility and sterility, vol. 95, no. 1, pp. 423-426, 2011.

[117] G. T. J. Huang, S. Gronthos, and S. Shi, "Mesenchymal stem cells derived from dental tissues vs. those from other sources: their biology and role in regenerative medicine," Journal of dental research, vol. 88, no. 9, pp. 792-806, 2009.
[118] J. G. Allickson, A. Sanchez, N. Yefimenko, C. V. Borlongan, and P. R. Sanberg, "Recent studies assessing the proliferative capability of a novel adult stem cell identified in menstrual blood," The open stem cell journal, vol. 3, no. 1, pp. 4-10, 2011.

[119] R. Ab Kadir, S. H. Zainal Ariffin, R. Megat Abdul Wahab, S. Kermani, and S. Senafi, "Characterization of mononucleated human peripheral blood cells," The Scientific World Journal, vol. 2012, Article ID 843843, 8 pages, 2012.

[120] G. Bartsch, J. J. Yoo, P. de Coppi et al., "Propagation, expansion, and multilineage differentiation of human somatic stem cells from dermal progenitors," Stem cells and development, vol. 14, no. 3, pp. 337-348, 2005.

[121] T. Morito, T. Muneta, K. Hara et al., "Synovial fluid-derived mesenchymal stem cells increase after intra-articular ligament injury in humans," Rheumatology, vol. 47, no. 8, pp. 1137-1143, 2008.

[122] H. Wang, S. C. Hung, S. T. Peng et al., "Mesenchymal stem cells in the Wharton's jelly of the human umbilical cord," Stem Cells, vol. 22, no. 7, pp. 1330-1337, 2004.

[123] K. BlancLe and D. Mougiakakos, "Multipotent mesenchymal stromal cells and the innate immune system," Nature Reviews Immunology, vol. 12, no. 5, pp. 383-396, 2012.

[124] B. Sacchetti, A. Funari, S. Michienzi et al., "Self-renewing osteoprogenitors in bone marrow sinusoids can organize a hematopoietic microenvironment," Cell, vol. 131, no. 2, pp. 324-336, 2007.

[125] I. U. Schraufstatter, R. G. Discipio, and S. Khaldoyanidi, "Mesenchymal stem cells and their microenvironment," Frontiers in Bioscience, vol. 16, no. 1, pp. 2271-2288, 2011.

[126] M. Dominici, K. le Blanc, I. Mueller et al., "Minimal criteria for defining multipotent mesenchymal stromal cells. The International Society for Cellular Therapy position statement," Cytotherapy, vol. 8, no. 4, pp. 315-317, 2006.

[127] K. W. Witwer, B. W. M. van Balkom, S. Bruno et al., "Defining mesenchymal stromal cell (MSC)-derived small extracellular vesicles for therapeutic applications," Journal of extracellular vesicles, vol. 8, no. 1, article 1609206, 2019.

[128] H. Ghaneialvar, L. Soltani, H. R. Rahmani, A. S. Lotfi, and M. Soleimani, "Characterization and classification of mesenchymal stem cells in several species using surface markers for cell therapy purposes," Indian Journal of Clinical Biochemistry, vol. 33, no. 1, pp. 46-52, 2018.

[129] I. Nishimura, R. Hisanaga, T. Sato et al., "Effect of osteogenic differentiation medium on proliferation and differentiation of human mesenchymal stem cells in three-dimensional culture with radial flow bioreactor," Regenerative therapy, vol. 2, pp. 24-31, 2015.

[130] C. H. Chung, E. E. Golub, E. Forbes, T. Tokuoka, and I. M. Shapiro, "Mechanism of action of beta-glycerophosphate on bone cell mineralization," Calcified Tissue International, vol. 51, no. 4, pp. 305-311, 1992.

[131] D. J. Prockop and K. I. Kivirikko, "COLLAGENS: molecular biology, diseases, and potentials for Therapy," Annual review of biochemistry, vol. 64, no. 1, pp. 403-434, 1995.

[132] Z. Hamidouche, E. Haÿ, P. Vaudin et al., "FHL2 mediates dexamethasone-induced mesenchymal cell differentiation into osteoblasts by activating $\mathrm{Wnt} / \beta$-catenin signalingdependent Runx2 expression," The FASEB Journal, vol. 22, no. 11, pp. 3813-3822, 2008.

[133] J. Rungby, M. Kassem, E. F. Eriksen, and G. Danscher, "The Von Kossa reaction for calcium deposits: silver lactate 
staining increases sensitivity and reduces background," The Histochemical Journal, vol. 25, no. 6, pp. 446-451, 1993.

[134] H. Puchtler, S. N. Meloan, and M. S. Terry, "On the history and MECHANISM of alizarin and alizarin red S stains for calcium," Journal of Histochemistry \& Cytochemistry, vol. 17, no. 2, pp. 110-124, 1969.

[135] I. Bab, B. A. Ashton, G. T. Syftestad, and M. E. Owen, "Assessment of an in vivo diffusion chamber method as a quantitative assay for osteogenesis," Calcified tissue international, vol. 36, no. 1, pp. 77-82, 1984.

[136] P. Bourin, B. A. Bunnell, L. Casteilla et al., "Stromal cells from the adipose tissue-derived stromal vascular fraction and culture expanded adipose tissue-derived stromal/stem cells: a joint statement of the International Federation for Adipose Therapeutics and Science (IFATS) and the International Society for Cellular Therapy (ISCT)," Cytotherapy, vol. 15, no. 6, pp. 641-648, 2013.

[137] S. Gronthos, S. E. Graves, S. Ohta, and P. J. Simmons, "The STRO-1+ fraction of adult human bone marrow contains the osteogenic precursors," Blood, vol. 84, no. 12, pp. 41644173, 1994.

[138] A. Mildmay-White and W. Khan, "Cell surface markers on adipose-derived stem cells: a systematic review," Current Stem Cell Research \& Therapy, vol. 12, no. 6, pp. 484-492, 2017.

[139] C. Pendleton, Q. Li, D. A. Chesler, K. Yuan, H. Guerrerocazares, and A. Quinones-hinojosa, "Mesenchymal stem cells derived from adipose tissue vs bone marrow: in vitro comparison of their tropism towards gliomas," PLoS One, vol. 8, no. 3, article e58198, 2013.

[140] J. Ma, J. Wu, L. Han et al., "Comparative analysis of mesenchymal stem cells derived from amniotic membrane, umbilical cord, and chorionic plate under serum-free condition," Stem cell research \& therapy, vol. 10, no. 1, article 1104, pp. 1-13, 2019.

[141] L.-S. Spitzhorn, M. S. Rahman, L. Schwindt et al., "Isolation and molecular characterization of amniotic fluid-derived mesenchymal stem cells obtained from caesarean sections," Stem cells international, vol. 2017, Article ID 5932706, 15 pages, 2017.

[142] M. Tsai, J. Lee, Y. Chang, and S. Hwang, "Isolation of human multipotent mesenchymal stem cells from second-trimester amniotic fluid using a novel two-stage culture protocol," Human reproduction, vol. 19, no. 6, pp. 1450-1456, 2004.

[143] H.-J. Buhring, V. L. Battula, S. Treml, B. Schewe, L. Kanz, and W. VOGEL, "Novel markers for the prospective isolation of human MSC," Annals of the New York Academy of Sciences, vol. 1106, no. 1, pp. 262-271, 2007.

[144] K. Kadar, M. Kiraly, B. Porcsalmy et al., "Differentiation potential of stem cells from human dental origin-promise for tissue engineering," Journal of Physiology and Pharmacology, vol. 60, pp. 167-175, 2009.

[145] E. Ledesma-Martínez, V. M. Mendoza-Núñez, and E. Santiago-Osorio, "Mesenchymal stem cells derived from dental pulp: a review," Stem cells international, vol. 2016, Article ID 4709572, 12 pages, 2016.

[146] M. Khatun, A. Sorjamaa, M. Kangasniemi et al., "Niche matters: the comparison between bone marrow stem cells and endometrial stem cells and stromal fibroblasts reveal distinct migration and cytokine profiles in response to inflammatory stimulus," PLoS One, vol. 12, no. 4, article e0175986, 2017.
[147] R. Wiegner, N.-E. Rudhart, E. Barth et al., "Mesenchymal stem cells in peripheral blood of severely injured patients," European Journal of Trauma and Emergency Surgery, vol. 44, no. 4, pp. 627-636, 2018.

[148] W. Lin, L. Xu, S. Lin et al., "Characterisation of multipotent stem cells from human peripheral blood using an improved protocol," Journal of orthopaedic translation, vol. 19, pp. 18-28, 2019.

[149] S. Kim, S. K. Lee, H. Kim, and T. Kim, "Exosomes secreted from induced pluripotent stem cell-derived mesenchymal stem cells accelerate skin cell Proliferation," International journal of molecular sciences, vol. 19, no. 10, p. 3119, 2018.

[150] T. Coccini, U. De Simone, M. Roccio et al., "In vitro toxicity screening of magnetite nanoparticles by applying mesenchymal stem cells derived from human umbilical cord lining," Journal of Applied Toxicology, vol. 39, no. 9, pp. 1320-1336, 2019.

[151] D. Bharti, S. B. Shivakumar, J. Park et al., "Comparative analysis of human Wharton's jelly mesenchymal stem cells derived from different parts of the same umbilical cord," Cell and tissue research, vol. 372 , no. 1 , article 2699 , pp. 51-65, 2018.

[152] L. Xu, Y. Liu, Y. Sun et al., "Tissue source determines the differentiation potentials of mesenchymal stem cells: a comparative study of human mesenchymal stem cells from bone marrow and adipose tissue," Stem cell research \& therapy, vol. 8, no. 1, pp. 275-311, 2017.

[153] C. Shen, C. Yang, S. Xu, and H. Zhao, "Comparison of osteogenic differentiation capacity in mesenchymal stem cells derived from human amniotic membrane (AM), umbilical cord (UC), chorionic membrane (CM), and decidua (DC)," Cell \& bioscience, vol. 9, no. 1, pp. 1-11, 2019.

[154] P. E. Bunney, A. N. Zink, A. A. Holm, C. J. Billington, and C. M. Kotz, "Orexin activation counteracts decreases in nonexercise activity thermogenesis (NEAT) caused by high-fat diet," The American journal of sports medicine, vol. 176, pp. 139-148, 2017.

[155] Q. Sun, H. Nakata, M. Yamamoto, S. Kasugai, and S. Kuroda, "Comparison of gingiva-derived and bone marrow mesenchymal stem cells for osteogenesis," Journal of cellular and molecular medicine, vol. 23, no. 11, pp. 7592-7601, 2019.

[156] V. Pérez-Silos, A. Camacho-Morales, and L. Fuentes-Mera, "Mesenchymal stem cells subpopulations: application for orthopedic regenerative medicine," Stem cells international, vol. 2016, Article ID 3187491, 9 pages, 2016.

[157] C. McLeod and R. L. Mauck, "On the origin and impact of mesenchymal stem cell heterogeneity: new insights and emerging tools for single cell analysis," European cells \& materials, vol. 34, pp. 217-231, 2017.

[158] R. Contentin, M. Demoor, M. Concari et al., "Comparison of the chondrogenic potential of mesenchymal stem cells derived from bone marrow and umbilical cord blood intended for cartilage tissue engineering," Stem cell reviews and reports, vol. 16, no. 1, pp. 126-143, 2020.

[159] B. Barboni, V. Russo, V. Curini et al., "Gestational stage affects amniotic epithelial cells phenotype, methylation status, immunomodulatory and stemness properties," Stem cell reviews and reports, vol. 10, no. 5, pp. 725-741, 2014.

[160] T. Y. Xin, T. T. Yu, and R. L. Yang, "DNA methylation and demethylation link the properties of mesenchymal stem cells: regeneration and immunomodulation," World journal of stem cells, vol. 12, no. 5, pp. 351-358, 2020. 
[161] J. M. Murphy, K. Dixon, S. Beck, D. Fabian, A. Feldman, and F. Barry, "Reduced chondrogenic and adipogenic activity of mesenchymal stem cells from patients with advanced osteoarthritis," Arthritis \& Rheumatism, vol. 46, no. 3, pp. 704713, 2002.

[162] R. Cai, T. Nakamoto, T. Hoshiba, N. Kawazoe, and G. Chen, "Control of simultaneous osteogenic and adipogenic differentiation of mesenchymal stem cells," Stem Cell Research \& Therapy, vol. 4, no. 8, 2014.

[163] N. M. Vieira, E. Zucconi, C. R. Bueno Jr. et al., "Human multipotent mesenchymal stromal cells from distinct sources show different in vivo potential to differentiate into muscle cells when injected in dystrophic mice," Stem Cell Reviews and Reports, vol. 6, no. 4, pp. 560-566, 2010.

[164] K. Bieback, S. Kern, H. Klüter, and H. Eichler, "Critical parameters for the isolation of mesenchymal stem cells from umbilical cord blood," Stem Cells, vol. 22, no. 4, pp. 625-634, 2004.

[165] R. S. Waterman, S. L. Tomchuck, S. L. Henkle, and A. M. Betancourt, "A new mesenchymal stem cell (MSC) paradigm: polarization into a pro-inflammatory $\mathrm{MSC} 1$ or an immunosuppressive MSC2 phenotype," PLoS One, vol. 5, no. 4, article e10088, 2010.

[166] M. I. Elashry, S. T. Gegnaw, M. C. Klymiuk, S. Wenisch, and S. Arnhold, "Influence of mechanical fluid shear stress on the osteogenic differentiation protocols for equine adipose tissuederived mesenchymal stem cells," Acta histochemica, vol. 121, no. 3, pp. 344-353, 2019.

[167] J. E. J. Li, N. Kawazoe, and G. Chen, "Gold nanoparticles with different charge and moiety induce differential cell response on mesenchymal stem cell osteogenesis," Biomaterials, vol. 54, pp. 226-236, 2015.

[168] P. A. Sotiropoulou, S. A. Perez, M. Salagianni, C. N. Baxevanis, and M. Papamichail, "characterization of the optimal culture conditions for clinical scale production of human mesenchymal stem cells," Stem Cells, vol. 24, no. 2, pp. 462471, 2006.

[169] T. Rada, R. L. Reis, and M. E. Gomes, "Distinct stem cells subpopulations isolated from human adipose tissue exhibit different chondrogenic and osteogenic differentiation potential," Stem Cell Reviews and Reports, vol. 7, no. 1, pp. 64-76, 2011.

[170] N. Meuleman, T. Tondreau, A. Delforge et al., "Human marrow mesenchymal stem cell culture: serum-free medium allows better expansion than classical alpha-MEM medium," European journal of haematology, vol. 76, no. 4, pp. 309-316, 2006.

[171] M. Sasaki, R. Abe, Y. Fujita, S. Ando, D. Inokuma, and H. Shimizu, "Mesenchymal stem cells are recruited into wounded skin and contribute to wound repair by transdifferentiation into multiple skin cell type," the Journal of immunology, vol. 180, no. 4, pp. 2581-2587, 2008.

[172] P. A. Zuk, M. Zhu, H. Mizuno et al., "Multilineage cells from human adipose tissue: implications for cell-based therapies," Tissue engineering, vol. 7, no. 2, pp. 211-228, 2001.

[173] B. Bunnell, M. Flaat, C. Gagliardi, B. Patel, and C. Ripoll, "Adipose-derived stem cells: isolation, expansion and differentiation," Methods, vol. 45, no. 2, pp. 115-120, 2008.

[174] J. He, B. Jiang, Y. Dai et al., "Regulation of the osteoblastic and chondrocytic differentiation of stem cells by the extracellular matrix and subsequent bone formation modes," Biomaterials, vol. 34, no. 28, pp. 6580-6588, 2013.
[175] J. He, J. Guo, B. Jiang, R. Yao, Y. Wu, and F. Wu, “Directing the osteoblastic and chondrocytic differentiations of mesenchymal stem cells: matrix vs. induction media," Regenerative biomaterials, vol. 4, no. 5, pp. 269-279, 2017.

[176] H. I. Gungordu, M. Bao, S. van Helvert, J. A. Jansen, S. C. G. Leeuwenburgh, and X. F. Walboomers, "Effect of mechanical loading and substrate elasticity on the osteogenic and adipogenic differentiation of mesenchymal stem cells," Journal of tissue engineering and regenerative medicine, vol. 13, no. 12, pp. 2279-2290, 2019.

[177] E. Castrén, T. Sillat, S. Oja et al., "Osteogenic differentiation of mesenchymal stromal cells in two-dimensional and three-dimensional cultures without animal serum," Stem cell research \& therapy, vol. 6, no. 1, p. 167, 2015.

[178] M. Cimino, R. M. Gonçalves, C. C. Barrias, and M. C. L. Martins, "Xeno-free strategies for safe human mesenchymal stem/stromal cell expansion: supplements and coatings," Stem cells international, vol. 2017, Article ID 6597815, 13 pages, 2017.

[179] T. Okajcekova, J. Strnadel, M. Pokusa et al., "A comparative in vitro analysis of the osteogenic potential of human dental pulp stem cells using various differentiation Conditions," International journal of molecular sciences, vol. 21, no. 7, p. 2280, 2020.

[180] S. G. Walter, T. M. Randau, C. Hilgers et al., "Molecular and functional phenotypes of human bone marrow-derived mesenchymal stromal cells depend on harvesting Techniques," International journal of molecular sciences, vol. 21, no. 12, p. $4382,2020$.

[181] R. A. Musina, E. S. Bekchanova, A. V. Belyavskii, and G. T. Sukhikh, "Differentiation potential of mesenchymal stem cells of different origin," Bulletin of experimental biology and medicine, vol. 141, no. 1, pp. 147-151, 2006.

[182] S. Mohamed-Ahmed, I. Fristad, S. A. Lie et al., "Adiposederived and bone marrow mesenchymal stem cells: a donor-matched comparison," Stem cell research \& therapy, vol. 9, no. 1, pp. 168-215, 2018.

[183] K. Szöke, J. Daňková, M. Buzgo, E. Amler, J. E. Brinchmann, and E. Østrup, "The effect of medium composition on deposition of collagen type 1 and expression of osteogenic genes in mesenchymal stem cells derived from human adipose tissue and bone marrow," Process Biochemistry, vol. 59, pp. 321328, 2017.

[184] H.-T. Liao and C. T. Chen, "Osteogenic potential: comparison between bone marrow and adipose-derived mesenchymal stem cells," World journal of stem cells, vol. 6, no. 3, pp. 288-295, 2014.

[185] K. Bieback, A. Hecker, T. Schlechter et al., "Replicative aging and differentiation potential of human adipose tissuederived mesenchymal stromal cells expanded in pooled human or fetal bovine serum," Cytotherapy, vol. 14, no. 5, pp. 570-583, 2012.

[186] M. Kassem, "Mesenchymal stem cells: biological characteristics and potential clinical applications," Cloning and stem cells, vol. 6, no. 4, pp. 369-374, 2004.

[187] M. M. Bonab, K. Alimoghaddam, F. Talebian, S. H. Ghaffari, A. Ghavamzadeh, and B. Nikbin, "Aging of mesenchymal stem cell in vitro elongated," BMC cell biology, vol. 7, no. 1, pp. 14-17, 2006.

[188] G. Moll, S. Geißler, R. Catar et al., "Cryopreserved or Fresh Mesenchymal Stromal Cells: Only a Matter of Taste or Key to Unleash the Full Clinical Potential of MSC Therapy?," 
Biobanking and cryopreservation of stem cells, vol. 951, pp. 77-98, 2016.

[189] G. V. Røsland, A. Svendsen, A. Torsvik et al., "Long-term cultures of bone marrow-derived human mesenchymal stem cells frequently undergo spontaneous malignant transformation," Cancer research, vol. 69, no. 13, pp. 5331-5339, 2009.

[190] S. Gottipamula, M. S. Muttigi, U. Kolkundkar, and R. N. Seetharam, "Serum-free media for the production of human mesenchymal stromal cells: a review," Cell proliferation, vol. 46, no. 6, pp. 608-627, 2013.

[191] D. W. Jayme and S. R. Smith, "Media formulation options and manufacturing process controls to safeguard against introduction of animal origin contaminants in animal cell culture," Cytotechnology, vol. 33, no. 1/3, pp. 27-36, 2000.

[192] T. Burnouf, D. Strunk, M. B. C. Koh, and K. Schallmoser, "Human platelet lysate: replacing fetal bovine serum as a gold standard for human cell propagation?," Biomaterials, vol. 76, pp. 371-387, 2016.

[193] K. Bieback, "Platelet lysate as replacement for fetal bovine serum in mesenchymal stromal cell cultures," Transfusion Medicine and Hemotherapy, vol. 40, no. 5, pp. 326-335, 2013.

[194] J. Etulain, "Platelets in wound healing and regenerative medicine,” Platelets, vol. 29, no. 6, pp. 556-568, 2018.

[195] M. R. De Pascale, L. Sommese, A. Casamassimi, and C. Napoli, "Platelet derivatives in regenerative medicine: an update," Transfusion medicine reviews, vol. 29, no. 1, pp. 52-61, 2015.

[196] D. M. Dohan Ehrenfest, I. Andia, M. A. Zumstein, C.Q. Zhang, N. R. Pinto, and T. Bielecki, "Classification of platelet concentrates (platelet-rich plasma-PRP, platelet-rich fibrin-PRF) for topical and infiltrative use in orthopedic and sports medicine: current consensus, clinical implications and perspectives," Muscles, ligaments and tendons journal, vol. 4, pp. 3-9, 2014.

[197] C. Dessels, M. Potgieter, and M. S. Pepper, "Making the Switch: Alternatives to Fetal Bovine Serum for AdiposeDerived Stromal Cell Expansion," Frontiers in cell and developmental biology, vol. 4, 2016.

[198] F. Atashi, M. E. E. Jaconi, B. Pittet-Cuénod, and A. Modarressi, "Autologous platelet-rich plasma: a biological supplement to enhance adipose-derived mesenchymal stem cell expansion," Tissue Engineering Part C: Methods, vol. 21, no. 3, pp. 253-262, 2014

[199] L. F. Marques, T. Stessuk, I. C. C. Camargo, N. Sabeh Junior, L. D. Santos, and J. T. Ribeiro-Paes, "Platelet-rich plasma (PRP): methodological aspects and clinical applications," Platelets, vol. 26, no. 2, pp. 101-113, 2015.

[200] A. Oikonomopoulos, W. K. van Deen, A.-R. Manansala et al., "Optimization of human mesenchymal stem cell manufacturing: the effects of animal/xeno-free media," Scientific reports, vol. 5, no. 1, article 16570, 2015.

[201] I. Müller, S. Kordowich, C. Holzwarth et al., “Animal serumfree culture conditions for isolation and expansion of multipotent mesenchymal stromal cells from human BM," Cytotherapy, vol. 8, no. 5, pp. 437-444, 2006.

[202] D. G. Steele and C. A. Bramblett, The Anatomy and Biology of the Human Skeleton, Texas A\&M University Press, 1988.

[203] G. G. Walmsley, A. McArdle, R. Tevlin et al., "Nanotechnology in Bone Tissue Engineering," Nanomedicine, vol. 11, no. 5, pp. 1253-1263, 2015.
[204] E. J. Carbone, T. Jiang, C. Nelson, N. Henry, and K. W. H. Lo, "Small molecule delivery through nanofibrous scaffolds for musculoskeletal regenerative engineering," Nanomedicine, vol. 10, no. 8, pp. 1691-1699, 2014.

[205] U. Kneser, D. J. Schaefer, E. Polykandriotis, and R. E. Horch, "Tissue engineering of bone: the reconstructive surgeon's point of view," Journal of cellular and molecular medicine, vol. 10, no. 1, pp. 7-19, 2006.

[206] B. William, G. D. L. Jr, T. A. Einhorn et al., "Bone grafts and bone graft substitutes in orthopaedic trauma surgery a critical analysis," Journal of bone and joint surgery. American volume, vol. 89, pp. 649-658, 2007.

[207] K. W.-H. Lo, B. D. Ulery, K. M. Ashe, and C. T. Laurencin, "Studies of bone morphogenetic protein-based surgical repair," Advanced drug delivery reviews, vol. 64, no. 12, pp. 1277-1291, 2012.

[208] G. Wei and P. X. Ma, "Structure and properties of nanohydroxyapatite/polymer composite scaffolds for bone tissue engineering," Biomaterials, vol. 25, no. 19, pp. 4749-4757, 2004.

[209] J. Salgado, O. P. Coutinho, and R. L. Reis, "Bone tissue engineering: state of the art and future trends," Macromolecular bioscience, vol. 4, no. 8, pp. 743-765, 2004.

[210] A. Wang, Z. Tang, I.-H. Park et al., "Induced pluripotent stem cells for neural tissue engineering," Biomaterials, vol. 32, no. 22, pp. 5023-5032, 2011.

[211] A. L. Gamblin, M. A. Brennan, A. Renaud et al., "Bone tissue formation with human mesenchymal stem cells and biphasic calcium phosphate ceramics: the local implication of osteoclasts and macrophages," Biomaterials, vol. 35, no. 36, pp. 9660-9667, 2014.

[212] M. A. Brennan, A. Renaud, J. Amiaud et al., "Pre-clinical studies of bone regeneration with human bone marrow stromal cells and biphasic calcium phosphate," Stem cell research \& therapy, vol. 5, no. 5, pp. 114-115, 2014.

[213] M. A. Brennan, A. Renaud, F. Guilloton et al., "Inferior in vivo osteogenesis and superior angiogeneis of human AdiposeDerived Stem Cells Compared with bone marrow-derived stem cells cultured in xeno-free conditions," Stem Cells Translational Medicine, vol. 6, no. 12, pp. 2160-2172, 2017.

[214] Y. Diao, Q. Ma, F. Cui, and Y. Zhong, "Human umbilical cord mesenchymal stem cells: Osteogenesis in vivo as seed cells for bone tissue engineering," Journal of Biomedical Materials Research Part A: An Official Journal of The Society for Biomaterials, The Japanese Society for Biomaterials, and The Australian Society for Biomaterials and the Korean Society for Biomaterials, vol. 91A, no. 1, pp. 123-131, 2009.

[215] R. A. Perez and G. Mestres, "Role of pore size and morphology in musculo-skeletal tissue regeneration," Materials Science and Engineering: C, vol. 61, pp. 922-939, 2016.

[216] F. J. O. Brien, "Biomaterials \& scaffolds for tissue engineering," Materials today, vol. 14, no. 3, pp. 88-95, 2011.

[217] Y. Wen, S. Xun, M. Haoye et al., "3D printed porous ceramic scaffolds for bone tissue engineering: a review," Biomaterials science, vol. 5, no. 9, pp. 1690-1698, 2017.

[218] C. M. Cowan, Y. Y. Shi, O. O. Aalami et al., "Adipose-derived adult stromal cells heal critical-size mouse calvarial defects," Nature biotechnology, vol. 22, no. 5, pp. 560-567, 2004.

[219] G. Asatrian, Perivascular Stem Cells Induce Paracrinemediated Osteogenesis via Upregulation of Secreted Wntrelated Proteins, University of California, Los Angeles, 2018. 
[220] D. G. Phinney, "Biochemical heterogeneity of mesenchymal stem cell populations: clues to their therapeutic efficacy," Cell Cycle, vol. 6, no. 23, pp. 2884-2889, 2007.

[221] J. N. Harvestine, N. L. Vollmer, S. S. Ho, C. A. Zikry, M. A. Lee, and J. K. Leach, "Extracellular matrix-coated composite scaffolds promote mesenchymal stem cell persistence and osteogenesis," Biomacromolecules, vol. 17, no. 11, pp. 3524-3531, 2016.

[222] A. I. Hoch, V. Mittal, D. Mitra, N. Vollmer, C. A. Zikry, and K. Leach, "Cell-secreted matrices perpetuate the boneforming phenotype of differentiated mesenchymal stem cells," Biomaterials, vol. 74, pp. 178-187, 2016.

[223] M. L. Decaris, B. Y. Binder, M. A. Soicher, A. Bhat, and J. K. Leach, "Cell-derived matrix coatings for polymeric scaffolds," Tissue engineering Part A, vol. 18, no. 19-20, pp. 2148-2157, 2012.

[224] J. Hum and A. Boccaccini, "Collagen as coating material for 45S5 bioactive glass-based scaffolds for bone tissue Engineering," International journal of molecular sciences, vol. 19, no. 6, p. $1807,2018$.

[225] A. Ehterami, M. Kazemi, B. Nazari, P. Saraeian, and M. Azami, "Fabrication and characterization of highly porous barium titanate based scaffold coated by Gel/HA nanocomposite with high piezoelectric coefficient for bone tissue engineering applications," Journal of the mechanical behavior of biomedical materials, vol. 79, pp. 195-202, 2018.

[226] A. Khojasteh, F. Fahimipour, M. B. Eslaminejad et al., "Development of PLGA-coated $\beta$-TCP scaffolds containing VEGF for bone tissue engineering," Materials Science and Engineering: $C$, vol. 69, pp. 780-788, 2016.

[227] K. C. Hicok, T. V. du Laney, Y. S. Zhou et al., "Human adipose-derived adult stem cells produce osteoid in vivo," Tissue engineering, vol. 10, no. 3-4, pp. 371-380, 2004.

[228] W. Hao, Y. Y. Hu, Y. Y. Wei et al., "Collagen I gel can facilitate homogenous bone formation of adipose-derived stem cells in PLGA-\&beta;-TCP scaffold," Cells Tissues Organs, vol. 187, no. 2, pp. 89-102, 2008.

[229] Y. Liu, Y. Zhou, H. Feng, G. e. Ma, and Y. Ni, "Injectable tissue-engineered bone composed of human adiposederived stromal cells and platelet-rich plasma," Biomaterials, vol. 29, no. 23, pp. 3338-3345, 2008.

[230] O. Jeon, J. W. Rhie, I.-K. Kwon, J.-H. Kim, B.-S. Kim, and S.$\mathrm{H}$. Lee, "In vivo bone formation following transplantation of human adipose-derived stromal cells that are not differentiated osteogenically," Tissue Engineering Part A, vol. 14, no. 8, pp. 1285-1294, 2008.

[231] L. Fan, J. Fan, Y. Liu et al., "MiR-450b promotes osteogenic differentiation in vitro and enhances bone formation in vivo by targeting BMP3," Stem cells and development, vol. 27, no. 9, pp. 600-611, 2018.

[232] K. Yanagihara, S. Uchida, S. Ohba, K. Kataoka, and K. Itaka, "Treatment of bone defects by transplantation of genetically modified mesenchymal stem cell spheroids," Molecular Therapy-Methods \& Clinical Development, vol. 9, pp. 358366, 2018.

[233] T. Lin, Y. Kohno, J. F. Huang et al., "Preconditioned or IL4secreting mesenchymal stem cells enhanced osteogenesis at different stages," Tissue Engineering Part A, vol. 25, no. 1516, pp. 1096-1103, 2019.

[234] A. H. Fischer, K. A. Jacobson, J. Rose, and R. Zeller, "Hematoxylin and eosin staining of tissue and cell sections," Cold spring harbor protocols, vol. 3, pp. 4986-4988, 2008.
[235] L. Zhang, M. Chang, C. A. Beck, E. M. Schwarz, and B. F. Boyce, "Analysis of new bone, cartilage, and fibrosis tissue in healing murine allografts using whole slide imaging and a new automated histomorphometric algorithm," Bone research, vol. 4, no. 1, article 15037, 2016.

[236] C. Montero, "The antigen-antibody reaction in immunohistochemistry," Journal of Histochemistry \& Cytochemistry, vol. 51, no. 1, pp. 1-4, 2003.

[237] M. Thorwarth, F. Wehrhan, S. Schultze-Mosgau, J. Wiltfang, and K. A. Schlegel, "PRP modulates expression of bone matrix proteins in vivo without long-term effects on bone formation," Bone, vol. 38, no. 1, pp. 30-40, 2006.

[238] Q. Zhang, L. Ma, S. Zheng et al., "Air-plasma treatment promotes bone-like nano-hydroxylapatite formation on protein films for enhanced in vivo osteogenesis," Biomaterials science, vol. 7, no. 6, pp. 2326-2334, 2019.

[239] J. Li, X. Wang, Y. Wang, C. Lu, D. Zheng, and J. Zhang, "Isoquercitrin, a flavonoid glucoside, exerts a positive effect on osteogenesis in vitro and in vivo," Chemico-biological interactions, vol. 297, pp. 85-94, 2019.

[240] B. Vesela, E. Svandova, M. Hovorakova et al., "Specification of Sprouty2 functions in osteogenesis in in vivo context," Organogenesis, vol. 15, no. 4, pp. 111-119, 2019.

[241] M. A. Brennan, J. M. Davaine, and P. Layrolle, "Pre-vascularization of bone tissue-engineered constructs," Stem cell research \& therapy, vol. 4, no. 4, p. 96, 2013.

[242] G. Fitzgerald, I. Soro-Arnaiz, and K. De Bock, "The Warburg effect in endothelial cells and its potential as an antiangiogenic target in cancer," Frontiers in cell and developmental biology, vol. 6, pp. 1-17, 2018.

[243] B. Peterson, J. Zhang, R. Iglesias et al., "Healing of critically sized femoral defects, using genetically modified mesenchymal stem cells from human adipose tissue," Tissue engineering, vol. 11, no. 1-2, pp. 120-129, 2005.

[244] D. Han and J. Li, "Repair of bone defect by using vascular bundle implantation combined with Runx II genetransfected adipose-derived stem cells and a biodegradable matrix," Cell and tissue research, vol. 352, no. 3, pp. 561571, 2013.

[245] Q. Chen, Z. Yang, S. Sun et al., “Adipose-derived stem cells modified genetically _in vivo_ promote reconstruction of bone defects," Cytotherapy, vol. 12, no. 6, pp. 831-840, 2010.

[246] Q. Gu, H. Yang, and Q. Shi, "Macrophages and bone inflammation," Journal of Orthopaedic Translation, vol. 10, pp. 8693, 2017.

[247] A. García-García and I. Martin, "Extracellular matrices to modulate the innate immune response and enhance bone healing," Frontiers in immunology, vol. 10, pp. 1-8, 2019.

[248] G. van Niel, A. Raposo, C. Candalh et al., "Intestinal epithelial cells secrete exosome-like vesicles," Gastroenterology, vol. 121, no. 2, pp. 337-349, 2001.

[249] D. L. Kraitchman, M. Tatsumi, W. D. Gilson et al., "Dynamic imaging of allogeneic mesenchymal stem cells trafficking to myocardial infarction," Circulation, vol. 112, no. 10, pp. 1451-1461, 2005.

[250] C. Toma, W. R. Wagner, S. Bowry, A. Schwartz, and F. Villanueva, "Fate of culture-expanded mesenchymal stem cells in the microvasculature: in vivo observations of cell kinetics," Circulation research, vol. 104, no. 3, pp. 398-402, 2009.

[251] K. Kallmeyer, D. André-Lévigne, M. Baquié et al., "Fate of systemically and locally administered adipose-derived 
mesenchymal stromal cells and their effect on wound healing," Stem cells translational medicine, vol. 9, no. 1, pp. 131-144, 2020.

[252] M. Rojas, J. Xu, C. R. Woods et al., "Bone marrow-derived mesenchymal stem cells in repair of the injured lung," American journal of respiratory cell and molecular biology, vol. 33, no. 2, pp. 145-152, 2005.

[253] L. A. Ortiz, F. Gambelli, C. McBride et al., "Mesenchymal stem cell engraftment in lung is enhanced in response to bleomycin exposure and ameliorates its fibrotic effects," Proceedings of the National Academy of Sciences, vol. 100, no. 14, pp. 8407-8411, 2003.

[254] S. Bruno, C. Grange, M. C. Deregibus et al., "Mesenchymal stem cell-derived microvesicles protect against acute tubular injury," Journal of the American Society of Nephrology, vol. 20, no. 5, pp. 1053-1067, 2009.

[255] S. Bruno, C. Grange, F. Collino et al., "Microvesicles derived from mesenchymal stem cells enhance survival in a lethal model of acute kidney injury," PLoS One, vol. 7, no. 3, article e33115, 2012.

[256] F. Arslan, R. C. Lai, M. B. Smeets et al., "Mesenchymal stem cell-derived exosomes increase ATP levels, decrease oxidative stress and activate PI3K/Akt pathway to enhance myocardial viability and prevent adverse remodeling after myocardial ischemia/reperfusion injury," Stem cell research, vol. 10, no. 3, pp. 301-312, 2013.

[257] S. Bian, L. Zhang, L. Duan, X. Wang, Y. Min, and H. Yu, "Extracellular vesicles derived from human bone marrow mesenchymal stem cells promote angiogenesis in a rat myocardial infarction model," Journal of molecular medicine, vol. 92, no. 4, pp. 387-397, 2014.

[258] X. Teng, L. Chen, W. Chen, J. Yang, Z. Yang, and Z. Shen, "Mesenchymal stem cell-derived exosomes improve the microenvironment of infarcted myocardium contributing to angiogenesis and anti-inflammation," Cellular Physiology and Biochemistry, vol. 37, no. 6, pp. 2415-2424, 2015.

[259] A. van Koppen, J. A. Joles, B. W. M. van Balkom et al., "Human embryonic mesenchymal stem cell-derived conditioned medium rescues kidney function in rats with established chronic kidney disease," PLoS One, vol. 7, no. 6, article e38746, 2012.

[260] L. A. Reis, F. T. Borges, M. J. Simões, A. A. Borges, R. Sinigaglia-Coimbra, and N. Schor, "Bone marrowderived mesenchymal stem cells repaired but did not prevent gentamicin-induced acute kidney injury through paracrine effects in rats," PLoS One, vol. 7, no. 9, article e44092, 2012.

[261] Y. Zhou, H. Xu, W. Xu et al., "Exosomes released by human umbilical cord mesenchymal stem cells protect against cisplatin-induced renal oxidative stress and apoptosis in vivo and in vitro," Stem cell research \& therapy, vol. 4, no. 2, p. 34, 2013.

[262] R. Bonafede, I. Scambi, D. Peroni et al., "Exosome derived from murine adipose-derived stromal cells: Neuroprotective effect on in vitro model of amyotrophic lateral sclerosis," Experimental cell research, vol. 340, no. 1, pp. 150-158, 2016.

[263] Y. Zhang, M. Chopp, Y. Meng et al., "Effect of exosomes derived from multipluripotent mesenchymal stromal cells on functional recovery and neurovascular plasticity in rats after traumatic brain injury," Journal of neurosurgery, vol. 122, no. 4, pp. 856-867, 2015.

[264] D. Kim, H. Nishida, S. Y. An, A. K. Shetty, T. J. Bartosh, and D. J. Prockop, "Chromatographically isolated CD63+CD81+ extracellular vesicles from mesenchymal stromal cells rescue cognitive impairments after TBI," Proceedings of the National Academy of Sciences, vol. 113, no. 1, pp. 170-175, 2016.

[265] S. Gennai, A. Monsel, Q. Hao, J. Park, M. A. Matthay, and J. W. Lee, "Microvesicles derived from human mesenchymal stem cells restore alveolar fluid clearance in human lungs rejected for transplantation," American Journal of Transplantation, vol. 15, no. 9, pp. 2404-2412, 2015.

[266] A. Monsel, Y. Zhu, S. Gennai et al., “Therapeutic effects of human mesenchymal stem cell-derived microvesicles in severe pneumonia in mice," American journal of respiratory and critical care medicine, vol. 192, no. 3, pp. 324-336, 2015.

[267] J. M. Aliotta, M. Pereira, S. Wen et al., "Exosomes induce and reverse monocrotaline-induced pulmonary hypertension in mice," Cardiovascular research, vol. 110, no. 3, pp. 319-330, 2016.

[268] B. Zhang, M. Wang, A. Gong et al., "HucMSC-exosome mediated-Wnt4 signaling is required for cutaneous wound healing," Stem Cells, vol. 33, no. 7, pp. 2158-2168, 2015.

[269] B. Zhang, X. Wu, X. Zhang et al., "Human umbilical cord mesenchymal stem cell exosomes enhance angiogenesis through the Wnt $4 / \beta$-catenin pathway," Stem cells translational medicine, vol. 4, no. 5, pp. 513-522, 2015.

[270] Y. Nakamura, S. Miyaki, H. Ishitobi et al., "Mesenchymalstem-cell-derived exosomes accelerate skeletal muscle regeneration," FEBS letters, vol. 589, no. 11, pp. 1257-1265, 2015.

[271] X. Qi, J. Zhang, H. Yuan et al., "Exosomes secreted by human-induced pluripotent stem cell-derived mesenchymal stem cells repair critical-sized bone defects through enhanced angiogenesis and osteogenesis in osteoporotic rats," International journal of biological sciences, vol. 12 , no. 7 , pp. 836849, 2016.

[272] S. Zhang, W. C. Chu, R. C. Lai, S. K. Lim, J. H. P. Hui, and W. S. Toh, "Exosomes derived from human embryonic mesenchymal stem cells promote osteochondral regeneration," Osteoarthritis and cartilage, vol. 24, no. 12, pp. 2135-2140, 2016.

[273] B. Zhang, Y. Yin, R. C. Lai, S. S. Tan, A. B. H. Choo, and S. K. Lim, "Mesenchymal stem cells secrete immunologically active exosomes," Stem cells and development, vol. 23, no. 11, pp. 1233-1244, 2014.

[274] C. Y. Tan, R. C. Lai, W. Wong, Y. Y. Dan, S.-K. Lim, and H. K. Ho, "Mesenchymal stem cell-derived exosomes promote hepatic regeneration in drug-induced liver injury models," Stem cell research \& therapy, vol. 5, no. 3, p. 76, 2014.

[275] T. Sozen, L. Ozisik, and N. Calik Basaran, "An overview and management of osteoporosis," European journal of rheumatology, vol. 4, no. 1, pp. 46-56, 2017.

[276] K. Lippuner, "The future of osteoporosis treatment - a research update," Swiss medical weekly, vol. 142, 2012.

[277] R. S. Weinstein, P. K. Roberson, and S. C. Manolagas, "Giant osteoclast formation and long-term oral bisphosphonate therapy," New England Journal of Medicine, vol. 360, no. 1, pp. 53-62, 2009.

[278] Z. Wang, J. Goh, S. D. de et al., "Efficacy of bone marrowderived stem cells in strengthening osteoporotic bone in a rabbit model," Tissue engineering, vol. 12, no. 7, pp. 17531761, 2006.

[279] F. S.-H. Hsiao, C.-C. Cheng, S.-Y. Peng et al., "Isolation of therapeutically functional mouse bone marrow mesenchymal stem cells within $3 \mathrm{~h}$ by an effective single-step plastic- 
adherent method," Cell Proliferation, vol. 43, no. 3, pp. 235248, 2010.

[280] C. C. Wyles, M. T. Houdek, A. Behfar, and R. J. Sierra, "Mesenchymal stem cell therapy for osteoarthritis: current perspectives," Stem Cells and Cloning: Advances and Applications, vol. 8, pp. 117-124, 2015.

[281] J. M. Bert and S. I. Gasser, "Approach to the osteoarthritic knee in the aging athlete: debridement to osteotomy," Arthroscopy, vol. 18, no. 9, pp. 107-110, 2002.

[282] C. Eder, K. Schmidt-Bleek, S. Geissler et al., "Mesenchymal stromal cell and bone marrow concentrate therapies for musculoskeletal indications: a concise review of current literature," Molecular Biology Reports, vol. 47, no. 6, pp. 47894814, 2020.

[283] R. S. Marcucio, A. Nauth, P. V. Giannoudis et al., "Stem cell therapies in orthopaedic trauma," Journal of orthopaedic trauma, vol. 29, Supplement 12, pp. S24-S27, 2015.

[284] P. Šponer, S. Filip, T. Kučera et al., "Utilizing Autologous Multipotent Mesenchymal Stromal Cells and -Tricalcium Phosphate Scaffold in Human Bone Defects: A Prospective, Controlled Feasibility Trial," BioMed research international, vol. 2016, Article ID 2076061, 12 pages, 2016.

[285] M. Liebergall, J. Schroeder, R. Mosheiff et al., "Stem cellbased therapy for prevention of delayed fracture union: a randomized and prospective preliminary study," Molecular Therapy, vol. 21, no. 8, pp. 1631-1638, 2013.

[286] S. Giannotti, V. Bottai, M. Ghilardi et al., "Treatment of pseudoarthrosis of the upper limb using expanded mesenchymal stem cells: a pilot study," European Review for Medical and Pharmacological Sciences, vol. 17, no. 2, pp. 224-227, 2013.

[287] S. Giannotti, L. Trombi, V. Bottai et al., "Use of autologous human mesenchymal stromal cell/fibrin clot constructs in upper limb non-unions: long-term assessment," PLoS One, vol. 8, no. 8, article e73893, 2013.

[288] D. Dufrane, P.-L. Docquier, C. Delloye, H. A. Poirel, W. André, and N. Aouassar, "Scaffold-free threedimensional graft from autologous adipose-derived stem cells for large bone defect reconstruction: clinical proof of concept," Medicine (Baltimore), vol. 94, no. 50, article e2220, 2015.

[289] M. Marcacci, E. Kon, V. Moukhachev et al., "Stem cells associated with macroporous bioceramics for long bone repair: 6to 7-year outcome of a pilot clinical study," Tissue engineering, vol. 13, no. 5, pp. 947-955, 2007.

[290] R. Quarto, M. Mastrogiacomo, R. Cancedda et al., "Repair of large bone defects with the use of autologous bone marrow stromal cells," New England Journal of Medicine, vol. 344, pp. 385-386, 2001.

[291] S. Bajada, P. E. Harrison, B. A. Ashton, V. N. Cassar-Pullicino, N. Ashammakhi, and J. B. Richardson, "Successful treatment of refractory tibial nonunion using calcium sulphate and bone marrow stromal cell implantation," The Bone \& Joint Journal, vol. 89-B, no. 10, pp. 1382-1386, 2007. 